\title{
Floristic study of Hwangmaesan Mt.
}

\author{
Hye-Won KIM ${ }^{\dagger}$, Eun-Mi SUN ${ }^{\dagger}$, Kang-Hyup LEE, Jung Sim LEE, \\ Beom Kyun PARK, Tae-Young CHOI and Soo-Rang LEE ${ }^{*}$
}

Division of Forest Biodiversity, Korea National Arboretum, Pocheon 11187, Korea (Received 20 February 2020; Revised 27 May 2020; Accepted 19 June 2020)

\begin{abstract}
Hwangmaesan Mt. $(1,108 \mathrm{~m})$ is rich in forest biodiversity and is a part of the Sobaek mountain range located in Hapcheon-gun, Gyeongsang-do in Korea. Unfortunately, the biodiversity and ecosystem integrity of Hwangmaesan Mt. have recently been threatened by heavy human disturbances. We conducted thirteen field surveys between March and October of 2019 to investigate the vascular flora in Hwangmaesan Mt. Through this extensive survey, we found 628 taxa consisting of 106 families, 349 genera, 554 species, 16 subspecies, 48 varieties, and 10 forma. Based on a comparative analysis between the present findings and former flora reports, our results showed an increase by 28 percent in the number of taxa observed. Of the 628 taxa, dicotyledons made up the largest group (477 taxa, 76.0\%) followed by monocotyledons (120 taxa, 19.1\%). Endemic plants consisted of 16 taxa, with rare plants designated by the Korea Forest Service numbering 14 taxa. Ten taxa were listed on the Red list by the Ministry of the Environment. The floristic target species designated by the Ministry of the Environment numbered 75 taxa, whereas there were 42 taxa of invasive plants.
\end{abstract}

Keywords: flora, Hwangmaesan Mt., human disturbances, endemic species, invasive species, rare species

황매산 $(1,108 \mathrm{~m})$ 군립공원은 소백산맥 줄기로 영남의 소금강이라 불리며 지리적으로 동경 127'56'34.7"$128^{\circ} 00^{\prime} 57.3^{\prime \prime}$, 북위 $35^{\circ} 26^{\prime} 32.0^{\prime \prime}-35^{\circ} 30^{\prime} 52.2^{\prime \prime}$ 이며, 북쪽으로 는 월여산 $(862 \mathrm{~m})$, 동쪽으로는 허굴산 $(681 \mathrm{~m})$, 남쪽으로는 감암산 $(834 \mathrm{~m})$ 등과 인접하고 있고, 행정구역상으로는 경 상남도 합천군 대병면 가회면과 산청군 차황면 경계에 위 치한다.

식물구계지리학적으로는 남부아구계(South province)에 속하며(Lee and Yim, 1978), 식물 군계에서는 냉온대남부와 난온대북부에 해당한다(Yim and Kira, 1975). 황매산이 속한 합천군의 최근 5 년간 기상개황으로는(Korea Meteorological Administration, 2019) 연평균기온이 $13.6^{\circ} \mathrm{C}$ 였고, 최고기온 과 최저기온의 평균은 각각 $20.5^{\circ} \mathrm{C}, 7.8^{\circ} \mathrm{C}$ 였으며, 최근 10 년 연평균 강수량은 $1,357.4 \mathrm{~mm}$ 를 기록하였다.

황매산 지역에 대한 기존 식물상 연구로는 황매산 수목 원 조성을 위한 기초조사에서 관속식물상을 91과 289속 410종 61변종 10 품종 481분류군으로 보고한 바 있으며 (Hong et al., 2012), Han et al. (2010)에 의한 조사에서는 황 매산이 속한 합천군의 관속식물로 82 과 292속 427 종 4 아
종 49변종 9품종의 총 489분류군이 확인된 바 있다. 그러 나 Hong et al. (2012)의 조사는 포스터발표 결과만 나와 있 을 뿐 종 목록 등을 확인할 수 없었으며, Han et al. (2010)의 조사는 황매산에 대한 조사가 아닌 합천군 전체에 대한 조사로 황매산 식물상 조사로 볼 수 없어 황매산의 식물 다양성을 평가하고 기록해 두는 작업이 필요하다.

자연공원 계획을 위한 Shin (2010)의 보전가치평가에 따 르면 황매산의 능선부는 생태적 가치가 높은 핵심보전지 역으로 계곡부와 초지지역은 보전지역으로 평가된 생태 환경적 가치 또한 높다. 그러나 황매산은 지역의 대표적 인 관광지로서 봄에는 철쭉축제, 가을에는 억새축제 등 다양한 행사가 개최되는 장소이다. 또한, 황매산성과 영 화주제공원도 위치하여 사시사철 등산객과 관광객의 발 길이 끊이지 않는 관광지로서, 조경 사업 및 개발이 지속 적으로 이루어지고 있다. 특히 해발 $800 \mathrm{~m}$ 고지에 오토캠 핑장과 주차장이 있기에 심각한 자연생태계 교란이 일어 날 수 있으며, 같은 고도의 다른 산들에 비해 상대적으로 식생 파괴 및 외부 식물의 유입이 용이하다.

이에 본 연구는 황매산의 관속식물상을 파악하여 현재

$\dagger$ These authors contributed equally to this work

*Author for correspondence: ra1130@korea.kr 
의 기록을 남기는 동시에 식물다양성 보존 방안 및 외래 식물의 산림 내 추가유입 방지를 위한 기초자료로 활용하 고자 한다.

\section{재료 및 방법}

황매산 관속식물상을 알아보기 위하여 2019년 3월부터 동년 10 월까지 총 13 회에 걸쳐 현지조사를 수행하였다 (Fig. 1, Table 1). 조사의 범위는 황매산 $(1,108 \mathrm{~m})$ 일대로 계 곡부와 능선부를 중심으로 조사하였다. 조사의 결과물인 확증표본은 꽃이나 열매 등 생식기관이 있는 개체로 채집 하였으며, 생식기관이 없거나 희귀식물의 경우는 사진을 찍어 확증표본을 대신하였고, 채집된 식물들은 압착 및 건조를 통해 석엽표본으로 제작되어 국립수목원 산림생 물표본관(KH)에 보관하였다. 표본의 동정은 Lee (1980,
1996) 등의 도감을 참고였으며, 분류군의 학명과 분류체 계는 국가표준식물목록(Korea National Arboretum, 2017) 을 기준으로 하고, 과 내에서는 알파벳 순서로 정리하였 다. 기타 식물목록은 특산식물목록(Chung et al., 2017), 고 유종목록(National Institute of Biological Resources, 2016), 희귀식물목록(Korea National Arboretum, 2008), 적색목록 (Shin et al., 2012), 식물구계학적특정종(National Institute of Ecology, 2018), 침입외래식물의 이해(Jung et al., 2016), 한 국의 귀화식물(Park, 2009)등에 근거하였다. 본 식물상 결 과와 기존 연구와 비교를 위해 기존자료를 검색하였으나 황매산 대상 식물상 자료가 없는 관계로 본 연구에서는 부득이하게 Hong et al. (2012)의 합천군 식물상 연구결과 와 비교·분석하였다. 비교 분석 대상에는 조사결과 분류 군 수, 교란식물 분류군 수, 희귀 및 특산식물 분류군 등을 포함하였다.

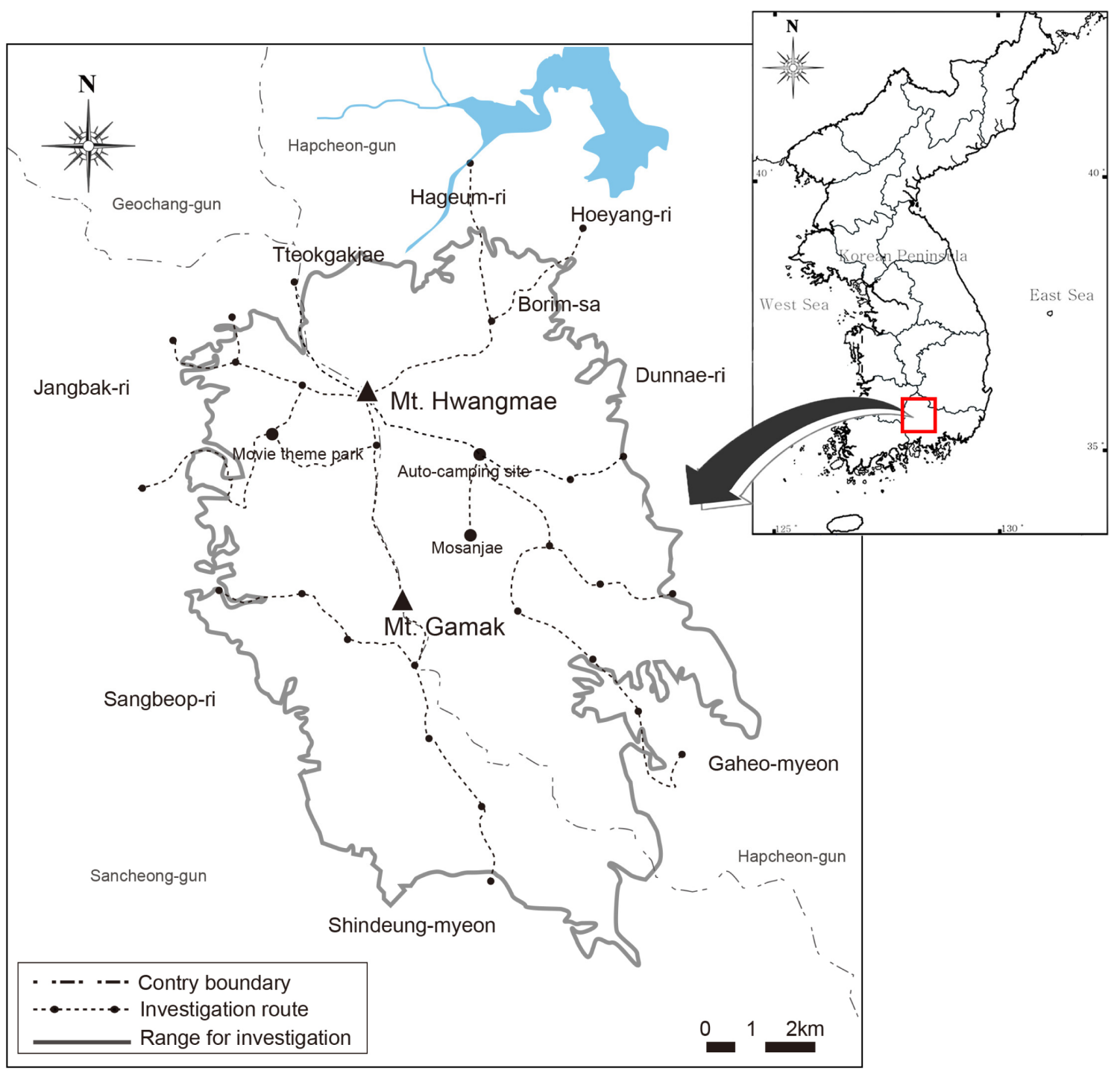

Fig. 1. Map of investigated area and routes. 
Table 1. The dates and routes of field survey in Hwangmaesan Mt.

\begin{tabular}{|c|c|c|}
\hline Date & No. & Investigation routs \\
\hline \multirow[t]{2}{*}{20 May 2019} & 1 & Sancheong-gun, Chawang-myeon, Jangbak-ri $\rightleftarrows$ Hwangsangol, near valleys \\
\hline & 2 & Sancheong-gun, Chawang-myeon, Sangbub-ri $\rightleftarrows$ Bokji-gol \\
\hline 10 Apr 2019 & 3 & Hapcheon-gun, Gaheo-myeon, Hwangmaesangongwon-gil $\rightleftarrows$ Auto camping site $\rightleftarrows$ Ticket office \\
\hline 11 Apr 2019 & 4 & Hapcheon-gun, Daegyung-myeon, Hakum-ri $\rightleftarrows$ Haewol pond \\
\hline 15 May 2019 & 5 & Hapcheon-gun, Gahoe-myeon, Hwangmaesangongwon-gil $\rightleftarrows$ Auto camping site $\rightleftarrows$ Peak $(1,108 \mathrm{~m})$ \\
\hline 16 May 2019 & 6 & Hapcheon-gun, Daegyung-myeon, Heoyang-ri, Borim-sa $\rightleftarrows$ Sports park \\
\hline 3 Jun 2019 & 7 & Hapcheon-gun, Daegyung-myeon, Hakum-ri $\rightleftarrows$ Borim-sa $\rightleftarrows$ Sports park \\
\hline \multirow[t]{2}{*}{4 Jun 2019} & 8 & Hapcheon-gun, Daegyung-myeon, Heoyang-ri, Borim-sa $\rightleftarrows$ Sports park \\
\hline & 9 & Hapcheon-gun, Daegyung-myeon, Daeji-ri, San68 Ddukgal-jae $\rightleftarrows$ Hakum valley \\
\hline \multirow[t]{2}{*}{28 Aug 2019} & 10 & Sancheong-gun, Chawang-myeon, Jangbak-ri, Jangbak village $\rightleftarrows$ Peak $(1,108 \mathrm{~m}) \rightleftarrows$ Bypath $\rightleftarrows$ Cinema park \\
\hline & 11 & Sancheong-gun, Chawang-myeon, Bubpyung-ri $\rightleftarrows$ Bypath $\rightleftarrows$ Cinema park \\
\hline 30 Sep 2019 & 12 & Sancheong-gun, Chawang-myeon, Jangbak-ri, Jangbak village $\rightleftarrows$ Peak $(1,108 \mathrm{~m}) \gtrless$ Bypath $\rightleftarrows$ Cinema park \\
\hline 1 Oct 2019 & 13 & Hapcheon-gun, Gaheo-myeon, Mosan-jae parking lot $\rightleftarrows$ Gijeok-gil $\rightleftarrows$ Auto camping site $\rightleftarrows$ Peak \\
\hline
\end{tabular}

Table 2. The number of vascular plants in Hwangmaesan Mt.

\begin{tabular}{lccccccc}
\hline \hline \multicolumn{1}{c}{ Taxa } & Family & Genus & Species & Subspecies & Variety & Forma & Total species and infraspecific taxa (\%) \\
\hline Pteriodophyta & 12 & 16 & 25 & - & 1 & - & $26(4.1)$ \\
Gymnospermae & 3 & 5 & 5 & - & - & - & $5(0.8)$ \\
Angiospermae & & & & & & & $477(76.0)$ \\
$\quad$ Dicotyledonae & 81 & 261 & 417 & 16 & 37 & 7 & $120(19.1)$ \\
$\quad$ Monocotyledonae & 11 & 67 & 107 & 0 & 10 & 3 & $628(100)$ \\
Total & 107 & 349 & 554 & 16 & 48 & 10 & \\
\hline
\end{tabular}

\section{결과 및 고찰}

\section{관속식물상}

황매산 지역의 식물상을 조사한 결과, 106 과 349 속 554 종 16 아종 48 변종 10 품종의 총 628 분류군을 확인할 수 있었다. 이는 국가표준식물목록(Korea National Arboretum, 2017)에 따른 한반도 자생식물 및 귀화, 외래 식물 4,364 분류군의 약 $14.4 \%$ 에 해당하며, 이 중 양치식 물은 26 분류군 $(4.1 \%)$, 나자식물은 5 분류군 $(0.8 \%)$, 쌍자 엽식물은 477 분류군 $(76.0 \%)$, 단자엽식물 120 분류군 (19.1\%) 이었다(Table 2). 이는 기존 조사인 황매산의 관 속식물상 481분류군(Hong et al., 2012), 합천군 관속식물 상 489분류군(Han et al., 2010)에 비하면 약 $28 \%$ 의 분류 군이 증가한 것이다. 기존 조사들에서 수목류의 보고가 상대적으로 미흡했던 것에 비해, 본 조사에서 전형적인 남부수종인 개비자나무[Cephalotaxus harringtonii (Knight ex J.Forbes) K. Koch], 굴피나무(Platycarya strobilacea Siebold \& Zucc.), 소사나무(Carpinus turczaninowii Hance), 푸조나무[Aphananthe aspera (Thunb.) Planch.], 사람주나무[Neoshirakia japonica
(Siebold \& Zucc.) Esser], 길마가지나무(Lonicera harae Makino) 등과 같은 수목들이 추가되었다.

\section{특산식물}

황매산의 한반도 특산식물은 개잠자리난초(Habenaria cruciformis Ohwi), 고려엉겅퀴[Cirsium setidens (Dunn) Nakai], 노각나무(Stewartia koreana Nakai ex Rehder), 닥나무 (Broussonetia $\times$ hanjiana M.Kim), 세잎승마[Actaea bifida (Nakai) J. Compton], 백운산원추리(Hemerocallis hakuunensis Nakai), 지리대사초(Carex okamotoi Ohwi) 등 총 12과 16속 16 분류군이며, 이는 우리나라 특산식물의 약 $4.4 \%$ 에 해당 한다(Table 3) (Chung et al., 2017).

Han et al. (2010)이 떡버들(Salix hallaisanensis H. Lèv.), 진 범(Aconitum pseudolaeve Nakai), 흰괭이눈[Chrysosplenium pilosum var. fulvum (N. Terracc.) Hara]의 세 분류군의 특산 식물을 확인한데 비해 본 조사에서는 은사시나무(Populus $\times$ tomentiglandulosa T. B. Lee), 키버들(Salix koriyanagi Kimura ex Goerz), 세잎승마[Actaea bifida (Nakai) J. Compton], 외대으아리(Clematis brachyura Maxim.) 등 10분 류군의 특산식물을 추가로 확인하였다(Table 3). 
Table 3. The list of endemic plants in Mt. Hwangmae designated by Korea National Arboretum.

\begin{tabular}{|c|c|c|c|c|}
\hline Family & Species or infraspecific taxa & Korean name & $2019^{\mathrm{a}}$ & $2012^{\mathrm{b}}$ \\
\hline \multirow[t]{3}{*}{ Salicaceae } & Populus $\times$ tomentiglandulosa T. B. Lee & 은사시나무 & $\mathrm{O}$ & - \\
\hline & Salix hallaisanensis H. Lèv & 떡버들 & - & $\mathrm{O}$ \\
\hline & Salix koriyanagi Kimura ex Goerz & 키버들 & $\mathrm{O}$ & - \\
\hline Caryophyllaceae & Pseudostellaria longipedicellata S. Lee, K. Heo \& S. C. Kim & 태백개별꽃 & $\mathrm{O}$ & - \\
\hline \multirow[t]{4}{*}{ Ranunculaceae } & Aconitum pseudolaeve Nakai & 진범 & - & $\mathrm{O}$ \\
\hline & Actaea bifida (Nakai) J.Compton & 세잎승마 & $\mathrm{O}$ & - \\
\hline & Clematis brachyura Maxim. & 외대으아리 & $\mathrm{O}$ & - \\
\hline & Thalictrum actaeifolium Siebold \& Zucc. & 은꿩의다리 & $\mathrm{O}$ & - \\
\hline Saxifragaceae & Chrysosplenium pilosum var. fulvum (N. Terracc.) Hara & 흰괭이눈 & - & $\mathrm{O}$ \\
\hline Oleaceae & Forsythia koreana (Rehder) Nakai & 개나리(Cultivated) & $\mathrm{O}$ & $\mathrm{O}$ \\
\hline Theaceae & Stewartia koreana Nakai ex Rehder & 노각나무 & $\mathrm{O}$ & - \\
\hline Moraceae & Broussonetia $\times$ hanjiana M.Kim & 닥나무 & $\mathrm{O}$ & - \\
\hline Scrophulariaceae & Paulownia coreana Uyeki & 오동나무 & $\mathrm{O}$ & $\mathrm{O}$ \\
\hline Caprifoliaceae & Weigela subsessilis (Nakai) L. H. Bailey & 병꽃나무 & $\mathrm{O}$ & $\mathrm{O}$ \\
\hline Asteraeae & Cirsium setidens (Dunn) Nakai & 고려엉겅퀴 & $\mathrm{O}$ & $\mathrm{O}$ \\
\hline \multirow[t]{2}{*}{ Liliaceae } & Hemerocallis hakuunensis Nakai & 백운산원추리 & $\mathrm{O}$ & - \\
\hline & Hosta minor (Baker) Nakai & 좀비비추 & $\mathrm{O}$ & - \\
\hline Cyperaceae & Carex okamotoi Ohwi & 지리대사초 & $\mathrm{O}$ & - \\
\hline Orchidaceae & Habenaria cruciformis Ohwi & 개잠자리난초 & $\mathrm{O}$ & - \\
\hline
\end{tabular}

${ }^{\mathrm{a}} 2019$ indicates presence of endemic species from the present survey. ${ }^{\mathrm{b}} 2012$ indicates presence of endemic species from Hong et al. (2012).

Table 4. The rare and endangered plants in Mt. Hwangmae listed in the Red Data book by Korea National Arboretum (KNA) and National Institute of Biological Resources (NIBR).

\begin{tabular}{|c|c|c|c|c|}
\hline \multirow{2}{*}{ Family } & \multirow{2}{*}{ Species } & \multirow{2}{*}{ Korean name } & \multicolumn{2}{|c|}{ Criteria } \\
\hline & & & $\mathrm{KNA}^{\mathrm{a}}$ & $\mathrm{NIBR}^{\mathrm{b}}$ \\
\hline Polypodiaceae & Selliguea hastata (Thunb.) Fraser-Jenk. & 고란초 & $\mathrm{LC}$ & - \\
\hline Cuppressaceae & Platycladus orientalis (L.) Franco & 측백나무(Cultivated) & $\mathrm{LC}$ & $\mathrm{LC}$ \\
\hline Berberidaceae & Epimedium koreanum Nakai & 삼지구엽초(Cultivated) & VU & - \\
\hline Chloranthaceae & Chloranthus fortunei (A.Gray) Solms & 옥녀꽃대 & DD & - \\
\hline Violaceae & Viola albida Palib. & 태백제비꽃 & $\mathrm{LC}$ & - \\
\hline Apiaceae & Bupleurum komarovianum Lincz. & 시호 & VU & - \\
\hline Boraginaceae & Trigonotis icumae (Maxim.) Makino & 덩굴꽃마리 & $\mathrm{LC}$ & $\mathrm{LC}$ \\
\hline Lamiaceae & Mosla japonica (Benth. ex Oliv.) Maxim. & 산들깨 & VU & $\mathrm{NE}$ \\
\hline Asteraceae & Inula salicina $\mathrm{L}$. & 버들금불초 & VU & - \\
\hline Asteraceae & Senecio argunensis Turcz. & 쑥방망이 & $\mathrm{VU}$ & NT \\
\hline Liliaceae & Lilium distichum Nakai ex Kamib. & 말나리 & $\mathrm{LC}$ & $\mathrm{LC}$ \\
\hline Iridaceae & Iris minutoaurea Makino & 금붓꽃 & VU & $\mathrm{LC}$ \\
\hline Orchidaceae & Habenaria cruciformis Ohwi & 개잠자리난초 & - & $\mathrm{LC}$ \\
\hline Orchidaceae & Platanthera hologlottis Maxim. & 흰제비란 & - & $\mathrm{LC}$ \\
\hline Orchidaceae & Pogonia minor (Makino) Makino & 방울새란 & VU & NT \\
\hline
\end{tabular}

LC, least concerned; VU, vulnerable; DD, data deficient; NE, not evaluated; NT, near threatened.

${ }^{a}$ Rare plants data book in Korea (Korean National Arboretum, 2008). ${ }^{\text {b }}$ Red data book of endangered vascular plants in Korea (National Institute of Biological Resources, 2012). 


\section{희귀식물 및 적색목록식물}

산림청이 지정한 희귀식물(Korea National Arboretum, 2008)로는 총 13 과 14 속의 14 분류군이 확인되었다. 약관심 종(least concerned, LC)인 고란초[Selliguea hastata (Thunb.) Fraser-Jenk.], 덩굴꽃마리[Trigonotis icumae (Maxim.) Makino], 말나리(Lilium distichum Nakai ex Kamib.), 태백제비꽃(Viola albida Palib.) 등 5 분류군, 취약종(vulnerable, VU)인 금붓꽃 (Iris minutoaurea Makino), 방울새란[Pogonia minor (Makino) Makino], 버들금불초(Inula salicina L.), 산들깨[Mosla japonica (Benth. ex Oliv.) Maxim.], 세잎승마 등 7분류군, 자 료부족종(data deficient, DD)인 옥녀꽃대[Chloranthus fortunei (A. Gray) Solms] 1분류군이었다. 이 중 오토캠핑장 주 변의 조경지역서 확인된 삼지구엽초(Epimedium koreamum Nakai, VU)와 측백나무[Platycladus orientalis (L.) Franco, $\mathrm{LC}$ 는 식재된 것으로 추측된다(Table 4).

적색목록식물은 총 8 과 10 속 10 분류군으로, 관심대상 (LC) 분류군은 개잠자리난초, 금붓꽃(Iris minutoaurea Makino), 덩굴꽃마리[Trigonotis icumae (Maxim.) Makino], 말나리(Lilium distichum Nakai ex Kamib.), 삼지구엽초, 측 백나무, 흰제비란(Platanthera hologlottis Maxim.)의 7분류 군이 조사되었다. 또한, 준위협종(near threatened, NT)으로 는 방울새란[Pogonia minor (Makino) Makino]과 쑥방망이 (Senecio argunensis Turcz.) 2분류군, 미평가종(not evaluated, $\mathrm{NE}$ )으로는 산들깨 1 분류군을 확인하였다(Table 4).
황매산을 포함한 합천군 일대에서는 2 종의 희귀식물 [다북떡쑥(Anaphalis sinica Hance), 흰참꽃나무(Rhododendron tschonoskii Maxim.)]이 분포하는것으로 보고된 바 있으나 (Han et al., 2010), 본 연구 결과 고란초, 덩굴꽃마리, 흰제 비란 등을 포함하여 총 15 분류군이 추가로 생육하는 것 으로 나타났다(Table 4).

\section{식물구계학적특정식물}

식물구계학적특정식물은 각 식물의 분포범위에 따라 I$\mathrm{V}$ 등급으로 구분되며, $\mathrm{I}$ 등급에서 $\mathrm{V}$ 등급으로 갈수록 제한된 구역에 분포함을 나타낸다. 황매산에서 확인된 식물구계학 적특정종은 43 과 63 속 7변종의 총 75 분류군으로 이는 황매 산에서 확인된 630 분류군의 $12.2 \%$ 에 해당한다(Table 5). I등 급종으로는 감태나무[Lindera glauca (Siebold \& Zucc.) Blume], 개미탑[Haloragis micrantha (Thunb.) R. Br.], 검은개선 갈퀴[Galium japonicum (Maxim.) Makino \& Nakai] 등 40분류 군이 조사되었으며, II등급종으로는 뀡고비(Osmunda cinnamomea L.), 동자꽃(Lychnis cognata Maxim.), 앵초 (Primula sieboldii E. Morren) 등 19분류군, III등급종은 산앵도 나무(Vaccinium hirtum var. koreanum (Nakai) Kitam.), 산쥐손이 (Geranium dahuricum DC.), 개서어나무(Carpinus tschonoskii Maxim.) 등 10 분류군, $\mathrm{IV}$ 등급종은 세잎승마, 파란여로 [Veratrum maackii var. parviflorum (Maxim. ex Miq.) H. Hara] 등 5 분류군, $\mathrm{V}$ 등급종으로는 흰제비란 1 분류군이 확인되었다.

Table 5. The list of floristic target species designated by the Ministry of Environment.

\begin{tabular}{|c|c|c|}
\hline Grade & 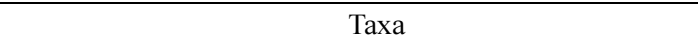 & Taxa \\
\hline \multirow[t]{16}{*}{ I } & \multicolumn{2}{|c|}{ Carpinus tschonoskii (Siebold \& Zucc.) Maxim. 개서어나무 Euonymus maackii Rupr. 회나무 } \\
\hline & Carpinus turczaninowii Hance 소사나무 & Euonymus sachalinensis (F. Schmidt) Maxim. 좁은잎참빗살나무 \\
\hline & Aphananthe aspera (Thunb.) Planch. 푸조나무 & Haloragis micrantha (Thunb.) R. Br. ex Siebold \& Zucc. 개미탑 \\
\hline & $\begin{array}{l}\text { Ulmus davidiana Planch. ex DC. var. japonica (Rehder) } \\
\text { Nakai 느릅나무 }\end{array}$ & $\begin{array}{l}\text { Eleutherococcus sessiliflorus (Rupr. \& Maxim.) S. Y. Hu } \\
\text { 오갈피나무 }\end{array}$ \\
\hline & Silene baccifera (L.) Roth 덩굴별꽃 & Ligustrum japonicum Thunb. 광나무(Cultivated) \\
\hline & Lindera erythrocarpa Makino 비목나무 & $\begin{array}{l}\text { Syringa pubescens Turcz. subsp. patula (Palib.) M. C. Chang \& X. } \\
\text { L. Chen 털개회나무 }\end{array}$ \\
\hline & Lindera glauca (Siebold \& Zucc.) Blume 감태나무 & Cynanchum ascyrifolium (Franch. \& Sav.) Matsum. 민백미꽃 \\
\hline & Aconitum jaluense Kom. 투구꽃 & Galium kinuta Nakai \& H. Hara 검은개선갈퀴 \\
\hline & Aconitum longecassidatum Nakai 흰진범 & Paederia foetida L. 계요등 \\
\hline & Clematis patens C. Morren \& Decne. 큰꽃으아리 & Trigonotis icumae (Maxim.) Makino 덩굴꽃마리 \\
\hline & Chloranthus fortunei (A. Gray) Solms 옥녀꽃대 & Ajuga decumbens Thunb. 금창초 \\
\hline & Deutzia glabrata Kom. 물참대 & Lycopus maackianus (Maxim. ex Herder) Makino 애기쉽싸리 \\
\hline & Deutzia parviflora Bunge 말발도리 & Viburnum opulus var. calvescens (Rehder) H.Hara 백당나무 \\
\hline & Deutzia uniflora Shirai 매화말발도리 & Adoxa moschatellina L. 연복초 \\
\hline & Filipendula glaberrima (Nakai) Nakai 터리풀 & Cirsium setidens (Dunn) Nakai 고려엉겅퀴 \\
\hline & Rosa lucieae Franch. \& Rochebr. ex Crép. 돌가시나무 & Saussurea odontolepis (Herder) Sch.Bip. ex Maxim. 빗살서덜취 \\
\hline
\end{tabular}


Table 5. The list of floristic target species designated by the Ministry of Environment.

\begin{tabular}{|c|c|c|}
\hline Grade & Taxa & Taxa \\
\hline \multirow[t]{4}{*}{ I } & Spiraea pubescens Turcz. 아구장나무 & Hosta capitata (Koidz.) Nakai 일월비비추 \\
\hline & Neoshirakia japonica (Siebold \& Zucc.) Esser 사람주나무 & Hosta minor (Baker) Nakai 좀비비추 \\
\hline & Dictamnus dasycarpus Turcz. 백선 & Iris minutoaurea Makino 금붓꽃 \\
\hline & Ilex macropoda Miq. 대팻집나무 & Carex okamotoi Ohwi 지리대사초 \\
\hline \multirow[t]{10}{*}{ II } & Osmunda cinnamomea L. 꿩고비 & Tripterygium regelii Sprague \& Takeda 미역줄나무 \\
\hline & Matteuccia struthiopteris (L.) Tod. 청나래고사리 & Tilia amurensis Rupr. 피나무 \\
\hline & Onoclea interrupta (Maxim.) Ching \& P. C. Chiu 야산고비 & Viola orientalis (Maxim.) W. Becker 노랑제비꽃 \\
\hline & Selliguea hastata (Thunb.) Fraser-Jenk. 고란초 & Cymopterus melanotilingia (H. Boissieu) C. Y. Yoon 큰참나물 \\
\hline & Lychnis cognata Maxim. 동자꽃 & Primula sieboldii E.Morren 앵초 \\
\hline & Schisandra chinensis (Turcz.) Baill. 오미자 & Weigela florida (Bunge) A. DC. 붉은병꽃나무 \\
\hline & Hylotelephium viviparum (Maxim.) H. Ohba 새끼꿩의비름 & Ligularia fischeri (Ledeb.) Turcz. 곰취 \\
\hline & $\begin{array}{l}\text { Potentilla ancistrifolia var. dickinsii (Franch. \& Sav.) Koidz. } \\
\text { 돌양지꽃 }\end{array}$ & Carex jaluensis Kom. 참삿갓사초 \\
\hline & Potentilla rosulifera H. Lév. 민눈양지꽃 & Epipactis thunbergii A. Gray 닭의난초 \\
\hline & Sorbus commixta Hedl. 마가목(Cultivated) & \\
\hline \multirow[t]{5}{*}{ III } & Betula davurica Pall. 물박달나무 N & Acer palmatum Thunb. 단풍나무 S \\
\hline & Clematis brachyura Maxim. 외대으아리 N & Vaccinium hirtum var. koreanum (Nakai) Kitam. 산앵도나무 N \\
\hline & Stewartia koreana Nakai ex Rehder 노각나무 S & Euphrasia maximowiczii Wettst. ex Palib. 앉은좁쌀풀 N \\
\hline & Philadelphus pekinensis Rupr. 애기고광나무(Cultivated) & Hosta clausa Nakai 주걱비비추 N \\
\hline & Geranium dahuricum DC. 산쥐손이 N & Lilium distichum Nakai ex Kamib 말나리 N \\
\hline \multirow[t]{3}{*}{ IV } & Thuja orientalis L. 측백나무(Cultivated) & Veratrum maackii var. parviflorum (Maxim. ex Miq.) H.Hara 파란여로 N \\
\hline & Cimicifuga heracleifolia var. bifida Nakai 세잎승마 N & Festuca rubra L. 왕김의털 N \\
\hline & Epimedium koreanum Nakai 삼지구엽초(Cultivated) & \\
\hline $\mathrm{V}$ & Platanthera hologlottis Maxim. 흰제비란 A & \\
\hline
\end{tabular}

$\mathrm{N}$, northern plants; S, southern plants; A, plants distributed in all areas of Korea.

\section{침입외래식물}

외래식물 목록은 귀화식물 관련 용어를 정리한 Jung et al. (2016) 및 Park (2009)의 기준에 따르면 벳지(Vicia villosa Roth.), 미국가막사리(Bidens frondosa L.), 오리새(Dactylis glomerata L.) 등을 포함한 총 15 과 37속 42분류군으로 나타 났다(Table 6). 이 중에는 환경부에서 생태계교란종으로 지 정한(Ministry of Environment, 2009) 가시상추(Lactuca serriola L.), 돼지풀(Ambrosia artemisiifolia L.), 애기수영 (Rumex acetosella L.), 미국쑥부쟁이[Symphyotrichum pilosum (Willd.) G. L. Nesom] 4분류군도 포함되었다.

본 조사에서는 Hong et al. (2012)의 합천군 지역의 조사 이후 최근 10 여 년 동안 새롭게 유입된 것으로 추정하는 침 입외래식물을 추가할 수 있었는데, 말뱅이나물[Vaccaria hispanica (Mill.) Rauschert], 벳지, 달맞이꽃(Oenothera biennis L.), 선개불알풀(Veronica arvensis L.), 큰개불알풀 (Veronica persica Poir.), 가시상추, 개쑥갓(Senecio vulgaris L.) 등이 그 대표적인 예이다.

\section{식생 및 식물지리학적 분포특성}

황매산은 온대남부 및 난온대북부 기후대에 위치한다. 식물구계는 감태나무, 사람주나무, 동백나무 (Camelia japonica L.) 등의 남부수종이 분포하는 남부아구에 속하 며, 북방계 식물과 남방계 식물이 혼생한다. 산정대는 낙 엽활엽수인 참나무가 군락을 이루는 전형적인 극상림을 보여준다. 산록대(500-600 m)는 소나무(Pinus densiflora Siebold \& Zucc.)와 참나무류의 혼효림으로 관목층은 국수 나무[Stephanandra incisa (Thunb.) Zabel], 병꽃나무[Weigela subsessilis (Nakai) L. H. Bailey], 쪽동백나무 등 낙엽활엽수 가 혼생하고, 중산간(해발 600-900 m)의 동쪽과 서쪽 사면 은 소나무 침엽수림이 우점한다. 동남쪽 계곡부는 뀡의바 람꽃(Anemone raddeana Regel), 앵초, 연복초(Adoxa moschatellina L.), 덩굴꽃마리 등이 계곡을 따라 산발적으로 군락을 이루고, 병꽃나무, 비목나무(Lindernea erythrocarpa Makino), 서어나무[Carpinus laxiflora (Siebold \& Zucc.) Blume], 상수리나무(Quercus acutissima Carruth.) 등 초본과 
Table 6. The list of invasive alien plants in Hwangmaesan Mt.

\begin{tabular}{|c|c|c|c|}
\hline Famliy & Species & Famliy & Species \\
\hline Salicaceae & $\begin{array}{l}\text { Populus } \times \text { canadensis Moench 이태리포푸라 } \\
\text { (Cultivated) }\end{array}$ & & Veronica persica Poir. 큰개불알풀 \\
\hline \multirow[t]{3}{*}{ Polygonaceae } & Fallopia dumetorum (L.) Holub 닭의덩굴 & Asteraceae & Achillea millefolium L. 서양톱풀 \\
\hline & Rumex acetosella L. 애기수영 & & Ambrosia artemisiifolia L. 돼지풀 \\
\hline & Rumex crispus L. 소리쟁이 & & Bidens frondosa L. 미국가막사리 \\
\hline Phytolaccaceae & Phytolacca americana L. 미국자리공 & & Bidens pilosa L. 울산도깨비바늘 \\
\hline Caryophillaceae & Vaccaria hispanica (Mill.) Rauschert 말뱅이나물 & & Conyza canadensis (L.) Cronquist 망초 \\
\hline Chenopodiaceae & Chenopodium ficifolium $\mathrm{Sm}$. 좀명아주 & & Coreopsis lanceolata L. 큰금계국 \\
\hline Amaranthaceae & Amaranthus hybridus L. 긴털비름 & & Cosmos bipinnatus Cav. 코스모스(Cultivated) \\
\hline Actinidiaceae & Actinidia chinensis 참다래 & & Crassocephalum crepidioides (Benth.) S. Moore 주홍서나물 \\
\hline Brassicaceae & Thlaspi arvense L. 말냉이 & & Erechtites hieraciifolius (L.) Raf. ex DC. 붉은서나물 \\
\hline Rosaceae & Chaenomeles sinensis 모과나무(Cultivated) & & Erigeron annuus (L.) Pers. 개망초 \\
\hline \multirow[t]{6}{*}{ Fabaceae } & Amorpha fruticosa L. 족제비싸리 & & Galinsoga ciliata (Raf.) S. F. Blak 털별꽃아재비 \\
\hline & Astragalus sinicus L. 자운영 & & Lactuca serriola L. 가시상추 \\
\hline & Robinia pseudoacacia L. 아까시나무 & & Senecio vulgaris $\mathrm{L}$. 개쑥갓 \\
\hline & Trifolium pratense L. 붉은토끼풀 & & Sonchus oleraceus L. 방가지똥 \\
\hline & Trifolium repens $\mathrm{L}$. 토끼풀 & & Symphyotrichum pilosum (Willd.) G. L. Nesom 미국쑥부쟁이 \\
\hline & Vicia villosa Roth 벳지 & & Tagetes patula L. 만수국 \\
\hline Onagraceae & Oenothera biennis L. 달맞이꽃 & & Taraxacum officinale F. H. Wigg. 서양민들레 \\
\hline Convolvulaceae & Ipomoea hederacea Jacq. 미국나팔꽃 & Poaceae & Dactylis glomerata L. 오리새 \\
\hline \multirow[t]{2}{*}{ Scrophulariaceae } & Veronica arvensis L. 선개불알풀 & & Festuca arundinacea Schreb. 큰김의털 \\
\hline & Veronica hederifolia L. 눈개불알풀 & & Zoysia japonica Steud. 잔디(Cultivated) \\
\hline
\end{tabular}

목본의 식물 다양성이 높은 지역이다. 산정대(해발 900$1,180 \mathrm{~m})$ 는 신갈나무, 상수리나무 등 참나무류가 우세하 고, 정상부에는 동자꽃, 빗살서덜취[Saussurea odontolepis (Herder) Sch. Bip. ex Maxim.], 노랑제비꽃(Viola orientalis Maxim.), 동자꽃, 터리풀[Filipendula glaberrima (Nakai) Nakai], 고려엉겅퀴 등 다수의 식물구계학적특정식물이 분포하고 있다.

본 지역에서 확인된 식물구계학적 특정식물 중 1 개 또 는 2개의 아구에 한하여 분포하는 3-5등급 식물은 식재종 을 제외하면 총 13 종이 확인되었다. 이 중 10 종은 북방계 식물로 나타났으며, 2종은 남방계식물이었고 1종은 전국 에 분포하나 불연속적으로 일부 지역에 국한되어 나타나 는 것으로 확인되었다. 또한 상기 식물구계학적특정식물 외에도 본 지역에는 조록싸리(Lespedeza maximowiczii C. K. Schneid.), 기린초[Phedimus kamtschaticus (Fisch. \& C. A. Mey.) 't Hart], 개복수초(Adonis pseudoamurensis W.T.Wang), 현호색(Corydalis remota Fisch. ex Maxim.), 산해박 [Cynanchum paniculatum (Bunge) Kitag. ex H. Hara], 산국 [Chrysanthemum boreale (Makino) Makino], 산달래(Allium macrostemon Bunge), 산철쭉[Rhododendron yedoense
Maxim. f. poukhanense (H. Lév.) Sugim. ex T. Yamaz.], 솜나 물[Leibnitzia anandria (L.) Turcz.], 얼레지(Erythronium japonicum Decne.), 젓가락나물(Ranunculus chinensis Bunge), 진달래(Rhododendron mucronulatum Turcz.), 파대 가리[Kyllinga brevifolia Rottb. var. leiolepis (Franch. \& Sav.) H. Hara] 등의 중국 동북지방 및 러시아 아무르지역에서 남하한 북방계 식물이 다수 분포하는 것으로 나타났다.

\section{종합고찰}

황매산은 군립공원으로 지정되어있는 별도관리지역이 나 자연공원 계획으로 북서쪽에 체육공원을 시작으로 남 서쪽 사면에 영화주제공원 $(760 \mathrm{~m})$, 동남쪽 사면에 오토캠 핑장 $(800 \mathrm{~m})$, 산정대에 철쭉군락과 억새 군락이 조성되어 산 전반에 걸쳐 관광지로 개발이 이루어진 상태이다.

본 지역은 남부아구계에 속함에도 불구하고, 발견된 대 부분의 식물구계학적 특정종은 기존에 남부 이북에 분포 하는 것으로 알려진 북방계 식물이며, 이 외에도 다수의 북방계 희귀식물이 남방계 식물과 더불어 출현하는 등 식 물지리학적 특이지역에 해당된다.

황매산에 분포하는 식물 중 특기할만한 종으로는 개잠 
자리난초, 흰제비란, 방울새란, 닭의난초, 앉은좁쌀풀 (Euphrasia maximowiczii Wettst. ex Palib.), 털향유(Galeopsis bifida Boenn.) 등을 확인하였다. 주로 산간습지나 습한 초 지에서 자라는 개잠자리난초, 방울새란 등의 난과 식물들 은 관상용, 약용의 용도로 남획되어 그 수가 급격히 줄 뿐 아니라(Lee et al., 2006) 기후변화에도 취약하며 개발로 인 해 습지가 축소하거나 소멸할 경우 그 지역에서 종이 사 라질 수 있는 가장 취약한 분류군 중 하나라 할 수 있으므 로 특별한 관심이 필요하다. 개잠자리난초는 산간습지 또 는 습한 초지에 생육하는 난과식물로 대부분 경기도 및 강원도 일부 지역에 분포하며, 황매산은 분포의 남한계에 해당한다(Lee, 2011). 본 지역에서는 정상으로 가는 남동 사면의 습한 초지에서 한두 개체 정도만이 남아 명맥을 유지하고 있었다. 흰제비란은 주로 높은 산지의 습지에 생육하고, 전국 각지에 불연속적으로 나타나는 것으로 알 려져 있으며(National Institute of Ecology, 2018), 황매산에 서는 개잠자리난초와 같은 곳에서 확인할 수 있었고 한 집단 정도가 무리를 이루고 있었다. 닭의난초는 내륙 또 는 해안산간습지에서 비교적 드물게 발견되는 종으로 $(\mathrm{Oh}$ et al., 2016) 황매산 서남사면에서 확인할 수 있었다. 한편, 남사면의 습한 초지에서는 방울새란과 털향유가 발견되 었다. 방울새란은 충남 서해안에 주로 생육하며 $(\mathrm{Oh}$ et al., 2016), 경남에서는 매우 드물게 나타난다. 털향유는 북방 계 식물로 금강산 이북에 분포하는 것으로 흔히 알려져 있으며, 남한에는 강원도(평창, 화천, 양구) 지역을 비롯하 여 소수의 개체군이 알려져 있다. 황매산은 본 종의 한반 도 내 분포 남한계에 해당하며, 향후 추가적인 식물지리 학적 연구가 필요할 것으로 사료된다. 앉은좁쌀풀은 주로 경남, 경북 지역에 분포하는데(Oh et al., 2016) 황매산에서 는 주차장에서 정상으로 향하는 남사면 초지에서 확인할 수 있었다.

희귀식물이면서 적색목록에 등록된 삼지구엽초나 측 백나무의 경우는 오토캠핑장(주차장)에서 정상으로 가는 조성지에 식재되어 있었으며, 식물구계학적 특정종인 광 나무(Ligustrum japonicum Thunb.; I등급), 마가목(Sorbus commixta Hedl.; II등급), 애기고광나무(Philadelphus pekinensis Rupr.; III등급), 삼지구엽초(IV등급), 측백나무(IV등급) 등 역시 식재되어 있었다. 사람들이 희귀식물을 쉽게 만나서 관심을 가지게 되는 것은 고무적인 일이라 할 수 있으나 산림지역에 식재하는 경우는 자생 여부에 혼란을 가져올 수 있고 종에 따라 생태계에 영향을 줄 수도 있음을 간과 해서는 안 될 것이다. 한편, 침입외래식물 중 생태계교란 종인 돼지풀은 저지대서부터 $810 \mathrm{~m}$ 고지대까지 고도별로 모두 분포하고 있었으며, 애기수영은 저지대는 물론 $1,098 \mathrm{~m}$ 정상부근에서도 발견되었으므로 분포지가 현재 이상으로 확산되지 않도록 특별한 관리가 필요할 것으로 보인다.

외래식물은 길 주변부에서 발생하고 번식할 확률이 높
으며 사실상 고산 숲에서는 생존경쟁력이 없어 유입되었 다가도 도태되는 경우가 많은 것으로 알려져 있다 (Mortensen, 2009). 그런 측면에서 바라볼 때, 황매산 남사 면은 자생 철쭉단지와 초지가 펼쳐진 곳으로 대부분 지역 이 햇볕이 매우 잘 드는 데다가 관광객의 편의를 위해 사 방으로 길을 넓게 내고 철쭉단지 안쪽으로도 인위적인 길 들을 만들었기에 외래식물이 유입되고 번식하기에 좋은 환경이므로 현재 외래식물의 번식뿐 아니라 추가적인 외 래식물의 유입도 우려된다. 관광지를 개발하고 지역발전 을 도모하는 것도 중요하나 개발 후 발생할 수 있는 생태 계의 위협요소를 예측하고 관리방안을 함께 만드는 노력 이 병행되어야 할 것이다.

ORCID: Hye-Won KIM 0000-0003-3131-2456; Eun-Mi SUN 0000-0001-7691-8094; Kang-Hyup LEE 0000-0002-71893235; Jung Sim LEE 0000-0003-2815-6464; Beom Kyun PARK 0000-0003-1894-3296; Tae-Young CHOI 0000-00026070-6676; Soo-Rang LEE 0000-0003-0277-4926

\section{Acknowledgments}

This study was supported by the project "KNA1-1-23, 181" funded by the Korea National Arboretum. We wish to express our sincere gratitude to Sabum Jang for his kind advise on identification and environment of the species. We would like to thank Donchan Son, Dongyun Oh, Aleksey Kim, Yumi Noh and Heesu Kim for their valuable support.

\section{Conflict of Interest}

The authors declare that there are no conflicts of interest.

\section{Literature Cited}

Chung, G. Y., K. S. Chang, J.-M. Chung, H. J. Choi, W.-K. Paik and J.-O. Hyun. 2017. A checklist of endemic plants on the Korean Peninsula. Korean Journal of Plant Taxonomy 47: 264-288. (in Korean)

Han, J.-W., H.-J. Kim, S.-H. Kang, S.-G. Yang, J.-M. Park and C.G. Jang. 2010. Distribution of vascular plants and plant resources characteristics in Hapcheon-gun, Gyeongsangnamdo Province: Mt. Odo, Mt. Hwangmae, Mt. Daeam, and Muweol Peak. Korean Journal of Environment and Ecology 24: 406-425. (in Korean)

Hong, S. H., G. O. Kim, Y. H. Lee, C. S. Na and Y. J. Oh. 2012. Flora of Hwangmaesan County Park planned area, Hapcheongun, Gyeongsang Province. In Symposium Booklet of the Plant Resources Society of Korea. The Plant Resources Soci- 
ety of Korea, Jecheon. P. 66. (in Korean)

Jung, S. Y., J. W. Lee, H. T. Shin, S. J. Kim, J. B. An, T. I. Heo, J. M. Chung and Y. C. Cho. 2016. Invasive Alien Plants in South Korea. Korea National Arboretum, Pocheon, 265 pp. (in Korean)

Korea National Arboretum. 2008. Rare Plants Data Book in Korea. Geobook Publishing Co., Pocheon, 332 pp. (in Korean)

Korea National Arboretum. 2017. Checklist of Vascular Plants in Korea. Korea National Arboretum, Pocheon, 1,000 pp. (in Korean)

Korea Meteorological Administration. 2019. Retrieved Dec. 18, 2019, available from http://kma.go.kr.

Lee, J.-S. and B.-H. Choi. 2006. Distributions and red data of wild orchids in the Korean peninsula. Korean Journal of Plant Taxonomy 36: 335-360. (in Korean)

Lee, N. S. 2011. Illustrated Flora of Korean Orchids. Ewha Womans University Press, Seoul, 345 pp. (in Korean)

Lee, T. B. 1980. Illustrations of Flora of Korea. Hyangmunsa, Seoul, Korea, 990 pp. (in Korean)

Lee, W. T. 1996. Coloured Standard Illustrations of Korean Plants. Academy Publishing Co., Seoul, 624 pp. (in Korean)

Lee, W.-T. and Y. J. Yim. 1978. Studies on the distribution of vascular plants in the Korean Peninsula. Korean Journal of Plant Taxonomy 8: 1-33. (in Korean)

Ministry of Environment. 2009. Ecosystem Disturbing Species. Ministry of Environment, Sejong, 138 pp. (in Korean)

Mortensen, D. A., E. S. J. Rauschert, A. N. Nord and B. P. Jones. 2009. Forest roads facilitate the spread of invasive plants. Invasive Plant Science and Management 2: 191-199.
National Institute of Biological Resources. 2016. Inventory and Management of Endemic Species of Korea. National Institute of Biological Research, Incheon, 159 pp. (in Korean)

National Institute of Ecology. 2018. Floristic Target Species (FT Species) in Korea. National Institute of Ecology, Seocheon, 728 pp. (in Korean)

Oh, B. U., S. C. Ko, S. H. Kang, W. K. Baek, K. E. Yoo, H. T. Yim, C. G. Jang, G. Y. Chung, B. H. Choi, H. J. Choi, Y. M. Lee, C. H. Shin, K. Choi, J. S. Han, S. H. Park, H. J. Kim, K. S. Chang, J. C. Yang, S. Y. Jung, C. H. Lee, S. H. Oh and D. G. Cho. 2016. Distribution Maps of Vascular Plants in Korea. Korea National Arboretum, Pocheon, 809 pp. (in Korean)

Park, S. H. 2009. New Illustrations and Photographs of Naturalized Plants of Korea. Ilchokak Publishing, Seoul, 575 pp. (in Korean)

Shin, H. C., Y. D. Kim, Y. S. Lim and Y. I. Kim. 2012. Red Data Book of Endangered Vascular Plants in Korea (Red Data Book 5). National Institute of Biological Resources, Incheon, 174 pp. (in Korean)

Shin, J.-H. 2010. A study on the natural park plan through ecological conservation value evaluation: a case study on $\mathrm{Mr}$. Hwangmaesan (Mt.) county park. Journal of Korea Society of Environmental Restoration Technology 13: 28-37. (in Korean)

Yim, Y. J. and T. Kira. 1975. Distribution of forest vegetation and climate in the Korean Peninsula. I. Distribution of some indices of thermal climate. Japanese Journal of Ecology 25: 7788. (in Korean)

\title{
황매산의 관속식물상
}

\section{김혜원 $^{\dagger} \cdot$ 선은미 $^{\dagger} \cdot$ 이강협 · 이정심 · 박범균 · 최태영 · 이수랑 ${ }^{*}$ \\ 국립수목원 산림생물다양성연구과}

\begin{abstract}
적 요: 경상남도 합천군과 산청군의 경계에 위치한 황매산 $(1,108 \mathrm{~m})$ 은 소백산맥의 줄기로 식생이 풍부하고 산림생물다양성이 높다. 그러나 지속적인 개발 및 등산객 등 관광객 증가와 함께 외래식물의 유입, 식재로 인한 생태계 교란 등의 문제가 우려되고 있다. 본 연구는 황매산의 관속식물상을 파악하여 현재의 기록을 남 기는 동시에 식물다양성 보존 방안 및 외래식물의 산림 내 추가유입 방지를 위한 기초자료로 활용하고자 계 획되었다. 조사는 2019년 3월부터 동년 10월까지 13회에 걸쳐 계절별로 개화하는 식물을 채집하고, 기록하 는 방식으로 이루어졌다. 조사 결과, 기존 조사에 비해 약 $28 \%$ 의 분류군이 증가한 106 과 349 속 554 종 16 아 종 48 변종 10 품종의 총 628 분류군을 확인하였다. 이는 국내 관속식물 4,364 분류군의 $14.4 \%$ 에 해당되며, 이 중 양치식물이 26 분류군 $(4.1 \%)$, 나자식물이 5 분류군 $(0.8 \%)$, 쌍자엽식물이 477 분류군 $(76.0 \%)$, 단자엽식물은 120 분류군(19.1\%)으로 분류되었다. 조사된 분류군 중 특산식물은 16 분류군, 산림청지정 희귀식물은 14 분류 군이었고, 침입외래식물은 42분류군, 환경부 지정 식물구계학적 등급종은 75 분류군으로 나타났다.
\end{abstract}

주요어: 황매산, 관속식물상, 인위적 교란, 특산식물, 외래종, 희귀식물 
Appendix 1. The list of vascular plants in Hwangmaesan Mt. The voucher specimens are deposited in KH.

\begin{tabular}{|c|c|c|c|}
\hline No. & Taxa & Korea name & Voucher number \\
\hline & Selaginellaceae 부처손과 & & \\
\hline \multirow[t]{2}{*}{1} & Selaginella rossii (Baker) Warb. & 구실사리 & LO04100256 \\
\hline & Equisetaceae 속새과 & & \\
\hline \multirow[t]{2}{*}{2} & Equisetum arvense $\mathrm{L}$. & 쇠뜨기 & Sun85927 \\
\hline & Ophioglossaceae 고사리삼과 & & \\
\hline 3 & Botrychium ternatum (Thunb.) Sw. & 고사리삼 & Sun91459 \\
\hline \multirow[t]{2}{*}{4} & Botrychium ternatum (Thunb.) Sw. & 광릉고사리삼 & LO04100152 \\
\hline & Osmundaceae 고비과 & & \\
\hline 5 & Osmunda cinnamomea $\mathrm{L}$. & 뀡고비 & 092353 \\
\hline \multirow[t]{2}{*}{6} & Osmunda japonica Thunb. & 고비 & Sun173907 \\
\hline & Dennstaedtiaceae 잔고사리과 & & \\
\hline 7 & Dennstaedtia hirsuta (Sw.) Mett. ex Miq. & 잔고사리 & LO04101205 \\
\hline 8 & Dennstaedtia wilfordii (T.Moore) Christ & 황고사리 & Sun104647 \\
\hline \multirow[t]{2}{*}{9} & Pteridium aquilinum (L.) Kuhn var. latiusculum (Desv.) Underw. ex A. Heller & 고사리 & Sun90314 \\
\hline & Aspleniaceae 꼬리고사리과 & & \\
\hline \multirow[t]{2}{*}{10} & Asplenium incisum Thunb. & 꼬리고사리 & LO04101035 \\
\hline & Thelypteridaceae 처녀고사리과 & & \\
\hline \multirow[t]{2}{*}{11} & Thelypteris palustris (A. Gray) Schott & 처녀고사리 & Sun93624 \\
\hline & Woodsiaceae 우드풀과 & & \\
\hline \multirow[t]{2}{*}{12} & Woodsia manchuriensis Hook. & 만주우드풀 & LOK190930027 \\
\hline & Onocleaceae 야산고비과 & & \\
\hline 13 & Matteuccia struthiopteris (L.) Tod. & 청나래고사리 & Sun172030 \\
\hline 14 & Onoclea interrupta (Maxim.) Ching \& P. C. Chiu & 야산고비 & Sun93424 \\
\hline \multirow[t]{2}{*}{15} & Pentarhizidium orientale (Hook.) Hayata & 개면마 & Sun155217 \\
\hline & Athyriaceae 개고사리과 & & \\
\hline 16 & Athyrium niponicum (Mett.) Hance & 개고사리 & LOK19093007 \\
\hline 17 & Athyrium yokoscense (Franch. \& Sav.) Christ & 뱀고사리 & LO04100153 \\
\hline 18 & Deparia japonica (Thunb.) M. Kato & 진고사리 & Sun134418 \\
\hline 19 & Deparia pseudoconilii (Seriz.) Seriz. & 나도좀진고사리 & LOK190930036 \\
\hline \multirow[t]{2}{*}{20} & Deparia ? angustata (Nakai) Nakaike & 개좀진고사리 & 125513 \\
\hline & Dryopteridaceae 관중과 & & \\
\hline 21 & Dryopteris chinensis (Baker) Koidz. & 가는잎족제비고사리 & Sun93443 \\
\hline 22 & Dryopteris lacera (Thunb.) Kuntze & 비늘고사리 & LO201996 \\
\hline 23 & Dryopteris sacrosancta Koidz. & 애기족제비고사리 & Sun190320_133941 \\
\hline 24 & Dryopteris setosa (Thunb.) Akasawa & 산족제비고사리 & Sun190320_134232 \\
\hline \multirow[t]{2}{*}{25} & Dryopteris uniformis (Makino) Makino & 곰비늘고사리 & Sun91524 \\
\hline & Polypodiaceae 관중과 & & \\
\hline \multirow[t]{2}{*}{26} & Selliguea hastata (Thunb.) Fraser-Jenk. & 고란초 & $120426-120$ \\
\hline & Pinaceae 소나무과 & & \\
\hline 27 & Larix kaempferi (Lamb.) Carrière & 일본잎갈나무 & Sun134335 \\
\hline
\end{tabular}


Appendix 1. Continued.

\begin{tabular}{|c|c|c|c|}
\hline No. & Taxa & Korea name & Voucher number \\
\hline \multirow[t]{2}{*}{28} & Pinus densiflora Siebold \& Zucc. & 소나무 & Sun112443 \\
\hline & Cupressaceae 측백나무과 & & \\
\hline 29 & Juniperus rigida Siebold \& Zucc. & 노간주나무 & LO04100156 \\
\hline \multirow[t]{2}{*}{30} & Platycladus orientalis (L.) Franco & $\begin{array}{c}\text { 측백나무 } \\
\text { (Cultivated) }\end{array}$ & LO04100950 \\
\hline & Cephalotaxaceae 개비자나무과 & & \\
\hline \multirow[t]{2}{*}{31} & Cephalotaxus harringtonii (Knight ex J. Forbes) K. Koch & 개비자나무 & Sun190320_135049 \\
\hline & Juglandaceae 가래나무과 & & \\
\hline \multirow[t]{2}{*}{32} & Platycarya strobilacea Siebold \& Zucc. & 굴피나무 & Sun100556 \\
\hline & Salicaceae 버드나무과 & & \\
\hline 33 & Populus $\times$ canadensis Moench & 이태리포푸라 & LO2019169 \\
\hline 34 & Populus $\times$ tomentiglandulosa T. B. Lee & 은사시나무 & 2019167 \\
\hline 35 & Salix caprea $\mathrm{L}$. & 호랑버들 & Sun190320_140909 \\
\hline 36 & Salix gracilistyla Miq. & 갯버들 & Sun104342 \\
\hline 37 & Salix koriyanagi Kimura ex Goerz & 키버들 & Sun190320_141440 \\
\hline 38 & Salix pierotii Miq. & 버드나무 & LO04101058 \\
\hline \multirow[t]{2}{*}{39} & Salix pseudolasiogyne H.Lév. & 능수버들 & LO201940 \\
\hline & Betulaceae 자작나무과 & & \\
\hline 40 & Alnus firma Siebold \& Zucc. & 사방오리 & Sun90246 \\
\hline 41 & Alnus incana (L.) Moench subsp. hirsuta (Turcz. ex Spach) Á. Löve \& D. Löve & 물오리나무 & Sun134503 \\
\hline 42 & Betula davurica Pall. & 물박달나무 & LO04110914 \\
\hline 43 & Carpinus laxiflora (Siebold \& Zucc.) Blume & 서어나무 & Sun93104 \\
\hline 44 & Carpinus tschonoskii (Siebold \& Zucc.) Maxi & 개서어나무 & LO201960 \\
\hline 45 & Carpinus turczaninowii Hance & 소사나무 & Sun90623 \\
\hline 46 & Corylus heterophylla Fisch. ex Trautv. & 난티잎개암나무 & LO04100140 \\
\hline 47 & Corylus sieboldiana Blume & 참개암나무 & Sun101342 \\
\hline \multirow[t]{2}{*}{48} & Corylus sieboldiana Blume var. mandshurica (Maxim.) C. K. Schneid. & 물개암나무 & LO201961 \\
\hline & Fagaceae 참나무과 & & \\
\hline 49 & Castanea crenata Siebold \& Zucc. & 밤나무 & Sun150724 \\
\hline 50 & Quercus acutissima Carruth. & 상수리나무 & Sun135730 \\
\hline 51 & Quercus aliena Blume & 갈참나무 & Sun113511 \\
\hline 52 & Quercus dentata Thunb. & 떡갈나무 & LO201952 \\
\hline 53 & Quercus mongolica Fisch. ex Ledeb. & 신갈나무 & LO04103953 \\
\hline 54 & Quercus serrata Murray & 졸참나무 & LO04100954 \\
\hline \multirow[t]{2}{*}{55} & Quercus variabilis Blume & 굴참나무 & Sun154711 \\
\hline & Ulmaceae 느릅나무과 & & \\
\hline 56 & Aphananthe aspera (Thunb.) Planch. & 푸조나무 & LO04103257 \\
\hline 57 & Ulmus davidiana Planch. ex DC. var. japonica (Rehder) Nakai & 느릅나무 & Sun113254 \\
\hline \multirow[t]{2}{*}{58} & Zelkova serrata (Thunb.) Makino & 느티나무 & Sun150914 \\
\hline & Moraceae 뽕나무과 & & \\
\hline
\end{tabular}


Appendix 1. Continued.

\begin{tabular}{|c|c|c|c|}
\hline No. & Taxa & Korea name & Voucher number \\
\hline 59 & Broussonetia $\times$ hanjiana M. Kim & 닥나무 & Sun141010 \\
\hline 60 & Fatoua villosa (Thunb.) Nakai & 뽕모시풀 & SKN191001079 \\
\hline 61 & Morus alba L. & 뽕나무 & LO2019100 \\
\hline \multirow[t]{2}{*}{62} & Morus australis Poir. & 산뽕나무 & Sun132513 \\
\hline & Cannabaceae 삼과 & & \\
\hline \multirow[t]{2}{*}{63} & Humulus scandens (Lour.) Merr. & 환삼덩굴 & Sun132928 \\
\hline & Urticaceae 쐐기풀과 & & \\
\hline 64 & Boehmeria platanifolia (Franch. \& Sav.) C. H. Wright & 개모시풀 & 144346 \\
\hline 65 & Boehmeria spicata (Thunb.) Thunb. & 좀깨잎나무 & Sun154713 \\
\hline \multirow[t]{2}{*}{66} & Boehmeria tricuspis (Hance) Makino var. unicuspis Makino ex Ohwi & 풀거북꼬리 & Sun145825 \\
\hline & Santalaceae 단향과 & & \\
\hline \multirow[t]{2}{*}{67} & Thesium chinense Turcz. & 제비꿀 & Sun80646 \\
\hline & Polygonaceae 마디풀과 & & \\
\hline 68 & Aconogonon alpinum (All.) Schur & 싱아 & $120907-067$ \\
\hline 69 & Fallopia dumetorum (L.) Holub & 닭의덩굴 & Sun132920 \\
\hline 70 & Persicaria filiformis (Thunb.) Nakai ex T.Mori & 이삭여뀌 & LO04110919 \\
\hline 71 & Persicaria lapathifolia (L.) Delarbre & 흰여뀌 & Sun90925 \\
\hline 72 & Persicaria longiseta (Bruijn) Kitag. & 개여뀌 & SKN191001092 \\
\hline 73 & Persicaria maackiana (Regel) Nakai ex T.Mori & 나도미꾸리낚시 & 100730 \\
\hline 74 & Persicaria nepalensis (Meisn.) H. Gross & 산여뀌 & Sun144812 \\
\hline 75 & Persicaria perfoliata (L.) H.Gross & 며느리배꼽 & Sun90252 \\
\hline 76 & Persicaria posumbu (Buch.-Ham. ex D. Don) H.Gross & 장대여뀌 & LOK190930068 \\
\hline 77 & Persicaria pubescens (Blume) H. Hara & 바보여뀌 & LO191001034 \\
\hline 78 & Persicaria sagittata $(\mathrm{L}$.$) H. Gross$ & 미꾸리낚시 & Sun93303 \\
\hline 79 & Persicaria senticosa (Meisn.) H. Gross ex Nakai & 며느리밑씻개 & Sun160745 \\
\hline 80 & Persicaria thunbergii (Siebold \& Zucc.) H. Gross & 고마리 & SKN191001001 \\
\hline 81 & Persicaria vulgaris Webb \& Moq. & 봄여뀌 & Sun181727 \\
\hline 82 & Polygonum aviculare $\mathrm{L}$. & 마디풀 & Sun144242 \\
\hline 83 & Rumex acetosa $\mathrm{L}$. & 수영 & Sun64618 \\
\hline 84 & Rumex acetosella $\mathrm{L}$. & 애기수영 & Sun63545 \\
\hline \multirow[t]{2}{*}{85} & Rumex crispus $\mathrm{L}$. & 소리쟁이 & Sun112534 \\
\hline & Phytolaccaceae 자리공과 & & \\
\hline \multirow[t]{2}{*}{86} & Phytolacca americana $\mathrm{L}$. & 미국자리공 & Sun150244 \\
\hline & Caryophyllaceae 석죽과 & & \\
\hline 87 & Arenaria serpyllifolia $\mathrm{L}$. & 벼룩이자리 & Sun64526 \\
\hline 88 & Cerastium holosteoides Fr. var. hallaisanense (Nakai) Mizush. & 점나도나물 & Sun63723 \\
\hline 89 & Dianthus longicalyx Miq. & 술패랭이꽃 & Sun123951 \\
\hline 90 & Lychnis cognata Maxim. & 동자꽃 & Sun130735 \\
\hline 91 & Pseudostellaria davidii (Franch.) Pax ex Pax \& Hoffm. & 덩굴개별꽃 & LO201947 \\
\hline 92 & Pseudostellaria davidii x palibiniana K. Choi \& J. H. Pak & 보현개별꽃 & LO04101154 \\
\hline
\end{tabular}


Appendix 1. Continued.

\begin{tabular}{|c|c|c|c|}
\hline No. & Taxa & Korea name & Voucher number \\
\hline 93 & Pseudostellaria heterophylla (Miq.) Pax & 개별꽃 & $120907-108$ \\
\hline 94 & Pseudostellaria longipedicellata S. Lee, K. Heo \& S. C. Kim & 태백개별꽃 & LO04101348 \\
\hline 95 & Pseudostellaria palibiniana (Takeda) Ohwi & 큰개별꽃 & Sun140942 \\
\hline 96 & Silene baccifera $(\mathrm{L}$.$) Roth$ & 덩굴별꽃 & Sun102640 \\
\hline 97 & Silene firma Siebold \& Zucc. & 장구채 & Sun105762 \\
\hline 98 & Silene seoulensis Nakai & 가는장구채 & 120052 \\
\hline 99 & Stellaria aquatica (L.) Scop. & 쇠별꽃 & LO04102409 \\
\hline 100 & Stellaria media (L.) Vill. & 별꽃 & Sun63950 \\
\hline 101 & Stellaria uliginosa Murray & 벼룩나물 & Sun143131 \\
\hline \multirow[t]{2}{*}{102} & Vaccaria hispanica (Mill.) Rauschert & 말뱅이나물 & Sun100735 \\
\hline & Chenopodiaceae 명아주과 & & \\
\hline \multirow[t]{2}{*}{103} & Chenopodium ficifolium $\mathrm{Sm}$. & 좀명아주 & Sun63724 \\
\hline & Amaranthaceae 비름과 & & \\
\hline 104 & Achyranthes bidentata Blume & 털쇠무를 & SKN191001089 \\
\hline \multirow[t]{2}{*}{105} & Amaranthus hybridus $\mathrm{L}$. & 긴털비름 & SKN191001060 \\
\hline & Schisandraceae 오미자과 & & \\
\hline \multirow[t]{2}{*}{106} & Schisandra chinensis (Turcz.) Baill. & 오미자 & Sun121700 \\
\hline & Lauraceae 녹나무과 & & \\
\hline 107 & Lindera erythrocarpa Makino & 비목나무 & Sun133247 \\
\hline 108 & Lindera glauca (Siebold \& Zucc.) Blume & 감태나무 & LO40100138 \\
\hline \multirow[t]{2}{*}{109} & Lindera obtusiloba Blume & 생강나무 & Sun105755 \\
\hline & Ranunculaceae 미나리아재비과 & & \\
\hline 110 & Aconitum jaluense Kom. & 투구꽃 & LOK190930056 \\
\hline 111 & Aconitum longecassidatum Nakai & 흰진범 & Sun111253 \\
\hline 112 & Aconitum pseudo-proliferum Nakai & 개싹눈바꽃 & Sun130358 \\
\hline 113 & Actaea bifida (Nakai) J. Compton & 세잎승마 & Sun105941 \\
\hline 114 & Adonis pseudoamurensis $\mathrm{W}$. T. Wang & 개복수초 & Sun155217 \\
\hline 115 & Anemone raddeana Regel & 뀡의바람꽃 & Sun132211 \\
\hline 116 & Clematis apiifolia DC. & 사위질빵 & LO04100932 \\
\hline 117 & Clematis brachyura Maxim. & 외대으아리 & Sun151000 \\
\hline 118 & Clematis patens $\mathrm{C}$. Morren \& Decne. & 큰꽃으아리 & Sun114465 \\
\hline 119 & Pulsatilla koreana (Y. Yabe ex Nakai) Nakai ex T. Mori & 할미꽃 & Sun190320_151257 \\
\hline 120 & Ranunculus cantoniensis DC. & 털개구리미나리 & Sun160512 \\
\hline 121 & Ranunculus chinensis Bunge & 젓가락나물 & Sun94535 \\
\hline 122 & Ranunculus japonicus Thunb. & 미나리아재비 & Sun65123 \\
\hline 123 & Ranunculus tachiroei Franch. \& Sav. & 개구리미나리 & 110616 \\
\hline 124 & Thalictrum actaeifolium Siebold \& Zucc. & 은뀡의다리 & Sun95133 \\
\hline 125 & Thalictrum minus (Pamp.) Pamp. var. hypoleucum (Siebold \& Zucc.) Miq. & 좀꿩의다리 & LO04100946 \\
\hline \multirow[t]{2}{*}{126} & Thalictrum tuberiferum Maxim. & 산뀡의다리 & Sun113558 \\
\hline & Berberidaceae 매자나무과 & & \\
\hline
\end{tabular}


Appendix 1. Continued.

\begin{tabular}{|c|c|c|c|}
\hline No. & Taxa & Korea name & Voucher number \\
\hline \multirow[t]{2}{*}{127} & Epimedium koreanum Nakai & $\begin{array}{l}\text { 삼지구엽초 } \\
\text { (Cultivated) }\end{array}$ & Sun64307 \\
\hline & Lardizabalaceae 으름덩굴과 & & \\
\hline \multirow[t]{2}{*}{128} & Akebia quinata (Houtt.) Decne. & 으름덩굴 & LO04100129 \\
\hline & Menispermaceae 방기과 & & \\
\hline \multirow[t]{2}{*}{129} & Cocculus orbiculatus (L.) DC. & 댕댕이덩굴 & LO04105844 \\
\hline & Chloranthaceae 홀아비꽃대과 & & \\
\hline \multirow[t]{2}{*}{130} & Chloranthus fortunei (A.Gray) Solms & 옥녀꽃대 & Sun93017 \\
\hline & Aristolochiaceae 쥐방울덩굴과 & & \\
\hline \multirow[t]{2}{*}{131} & Asarum sieboldii Miq. & 족도리풀 & Sun100702 \\
\hline & Actinidiaceae 다래나무과 & & \\
\hline 132 & Actinidia arguta (Siebold \& Zucc.) Planch. ex Miq. & 다래 & Sun155217 \\
\hline 133 & actinidia chinensis planch & $\begin{array}{c}\text { 참다래 } \\
\text { (Cultivated) }\end{array}$ & Sun144701 \\
\hline \multirow[t]{2}{*}{134} & Actinidia polygama (Siebold \& Zucc.) Planch. ex Maxim. & 개다래 & Sun112525 \\
\hline & Theaceae 차나무과 & & \\
\hline \multirow[t]{2}{*}{135} & Stewartia koreana Nakai ex Rehder & 노각나무 & LO04100203 \\
\hline & Clusiaceae 물레나물과 & & \\
\hline 136 & Hypericum ascyron $\mathrm{L}$. & 물레나물 & Sun91608 \\
\hline 137 & Hypericum erectum Thunb. & 고추나물 & Sun91848 \\
\hline \multirow[t]{2}{*}{138} & Hypericum japonicum Thunb. & 애기고추나물 & Sun91541 \\
\hline & Papaveraceae 양귀비과 & & \\
\hline 139 & Chelidonium majus L. subsp. asiaticum H.Hara & 애기똥풀 & LO04101812 \\
\hline 140 & Corydalis heterocarpa Siebold \& Zucc. & 염주괴불주머니 & LO04101008 \\
\hline 141 & Corydalis pauciovulata Ohwi & 선괴불주머니 & LOK190930030 \\
\hline 142 & Corydalis remota Fisch. ex Maxim. & 현호색 & Sun132058 \\
\hline 143 & Corydalis speciosa Maxim. & 산괴불주머니 & Sun145949 \\
\hline \multirow[t]{2}{*}{144} & Corydalis ternata (Nakai) Nakai & 들현호색 & LO04105901 \\
\hline & Brassicaceae 십자화과 & & \\
\hline 145 & Brassica napus L. & 유채 & Sun154327 \\
\hline 146 & Capsella bursa-pastoris (L.) Medik. & 냉이 & Sun190320_152007 \\
\hline 147 & Cardamine fallax (O. E. Schulz) Nakai & 좁쌀냉이 & Sun190320_134501 \\
\hline 148 & Cardamine flexuosa With. & 황새냉이 & Sun135401 \\
\hline 149 & Cardamine impatiens L. & 싸리냉이 & Sun140934 \\
\hline 150 & Cardamine leucantha (Tausch) O. E. Schulz & 미나리냉이 & 132606 \\
\hline 151 & Cardamine scutata Thunb. & 큰황새냉이 & LO04101004 \\
\hline 152 & Draba nemorosa L. & 꽃다지 & Sun190320_151940 \\
\hline 153 & Rorippa cantoniensis (Lour.) Ohwi & 좀개갓냉이 & LO04102146 \\
\hline 154 & Rorippa indica (L.) Hiern & 개갓냉이 & Sun90833 \\
\hline 155 & Thlaspi arvense $\mathrm{L}$. & 말냉이 & Sun150253 \\
\hline
\end{tabular}


Appendix 1. Continued.

\begin{tabular}{|c|c|c|c|}
\hline No. & Taxa & Korea name & Voucher number \\
\hline \multirow[t]{2}{*}{156} & Turritis glabra L. & 장대나물 & Sun133638 \\
\hline & Crassulaceae 돌나물과 & & \\
\hline 157 & Hylotelephium viviparum (Maxim.) H. Ohba & 새끼꿩의비름 & Sun121427 \\
\hline 158 & Orostachys japonica (Maxim.) A. Berger & 바위솔 & LO04101029 \\
\hline 159 & Phedimus aizoon (L.) 't Hart & 가는기린초 & Sun164639 \\
\hline 160 & Phedimus kamtschaticus (Fisch.) 't Hart & 기린초 & Sun101840 \\
\hline 161 & Sedum bulbiferum Makino & 말똥비름 & Sun161135 \\
\hline 162 & Sedum polytrichoides Hemsl. & 바위채송화 & Sun122735 \\
\hline \multirow[t]{2}{*}{163} & Sedum sarmentosum Bunge & 돌나물 & LO04100941 \\
\hline & Saxifragaceae 범의귀과 & & \\
\hline 164 & Astilbe chinensis (Maxim.) Franch. \& Sav. & 노루오줌 & Sun92843 \\
\hline \multirow[t]{2}{*}{165} & Saxifraga fortunei Hook. & 바위떡풀 & Sun125907 \\
\hline & Hydrangeaceae 수국과 & & \\
\hline 166 & Deutzia glabrata Kom. & 물참대 & Sun93447 \\
\hline 167 & Deutzia parviflora Bunge & 말발도리 & Sun154712 \\
\hline 168 & Deutzia uniflora Shirai & 매화말발도리 & Sun103743 \\
\hline 169 & Hydrangea macrophylla (Thunb.) Ser. subsp. serrata (Thunb.) Makino & 산수국 & LO04110915 \\
\hline 170 & Philadelphus pekinensis Rupr. & 애기고광나무 & $120614-110$ \\
\hline \multirow[t]{2}{*}{171} & Philadelphus tenuifolius Rupr. \& Maxim. & 얇은잎고광나무 & LO04101002 \\
\hline & Parnassiaceae 물매화과 & & \\
\hline \multirow[t]{2}{*}{172} & Parnassia palustris L. & 물매화 & Sun120907-053 \\
\hline & Rosaceae 장미과 & & \\
\hline 173 & Agrimonia pilosa Ledeb. & 짚신나물 & Sun90829 \\
\hline 174 & Chaenomeles sinensis koehne & 모과나무 & Sun140850 \\
\hline 175 & Duchesnea indica (Andrews) Focke & 뱀딸기 & LO04101024 \\
\hline 176 & Filipendula glaberrima (Nakai) Nakai & 터리풀 & Sun124438 \\
\hline 177 & Geum aleppicum Jacq. & 큰뱀무 & Sun141031 \\
\hline 178 & Geum japonicum Thunb. & 뱀무 & Sun133235 \\
\hline 179 & Kerria japonica (L.) DC. & $\begin{array}{c}\text { 황매화 } \\
\text { (Cultivated) }\end{array}$ & 104824 \\
\hline 180 & Kerria japonica f. pleniflora (Witte) Rehder & $\begin{array}{c}\text { 죽단화 } \\
\text { (Cultivated) }\end{array}$ & 93159 \\
\hline 181 & Malus toringo (Siebold) de Vriese & 아그배나무 & Sun110824 \\
\hline 182 & Photinia glabra (Thunb.) Maxim. & $\begin{array}{l}\text { 홍가시나무 } \\
\text { (Cultivated) }\end{array}$ & LO04101242 \\
\hline 183 & Potentilla ancistrifolia Bunge var. dickinsii (Franch. \& Sav.) Koidz. & 돌양지꽃 & Sun93742 \\
\hline 184 & Potentilla fragarioides $\mathrm{L}$. & 양지꽃 & Sun190320_151219 \\
\hline 185 & Potentilla freyniana Bornm. & 세잎양지꽃 & Sun85437 \\
\hline 186 & Potentilla kleiniana Wight \& Arn. & 가락지나물 & LO04100126 \\
\hline 187 & Potentilla rosulifera $\mathrm{H}$. Lév. & 민눈양지꽃 & LO04101132 \\
\hline 188 & Potentilla squamosa Soják & 털양지꽃 & Sun190320_152901 \\
\hline
\end{tabular}


Appendix 1. Continued.

\begin{tabular}{|c|c|c|c|}
\hline No. & Taxa & Korea name & Voucher number \\
\hline 189 & Prunus persica (L.) Stokes & 복사나무 & Sun162854 \\
\hline 190 & Prunus serrulata Lindl. var. pubescens (Makino) Nakai & 잔털벚나무 & Sun152312 \\
\hline 191 & Prunus serrulata Lindl. f. spontanea (E. H. Wilson) Chin S. Chang & 벚나무 & Sun105516 \\
\hline 192 & Pyrus ussuriensis Maxim. & 산돌배 & LO04100155 \\
\hline 193 & Rosa lucieae Franch. \& Rochebr. ex Crép. & 돌가시나무 & Sun150548 \\
\hline 194 & Rosa multiflora Thunb. & 찔레꽃 & Sun112640 \\
\hline 195 & Rubus crataegifolius Bunge & 산딸기 & Sun71709 \\
\hline 196 & Rubus parvifolius $\mathrm{L}$. & 멍석딸기 & LO04110853 \\
\hline 197 & Rubus phoenicolasius Maxim. & 곰딸기 & Sun171049 \\
\hline 198 & Rubus pungens Cambess. & 줄딸기 & Sun162546 \\
\hline 199 & Sanguisorba officinalis L. & 오이풀 & Sun124439 \\
\hline 200 & Sorbus alnifolia (Siebold \& Zucc.) K. Koch & 팥배나무 & LO04110923 \\
\hline 201 & Sorbus commixta Hedl. & $\begin{array}{c}\text { 마가목 } \\
\text { (Cultivated) }\end{array}$ & Sun131802 \\
\hline 202 & Spiraea japonica L.f. & 일본조팝나무 & Sun093057 \\
\hline 203 & Spiraea prunifolia Siebold \& Zucc. f. simpliciflora Nakai & 조팝나무 & Sun90157 \\
\hline 204 & Spiraea pubescens Turcz. & 아구장나무 & Sun122815 \\
\hline \multirow[t]{2}{*}{205} & Stephanandra incisa (Thunb.) Zabel & 국수나무 & Sun134256 \\
\hline & Fabaceae 콩과 & & \\
\hline 206 & Amorpha fruticosa $\mathrm{L}$. & 족제비싸리 & Sun175807 \\
\hline 207 & Amphicarpaea bracteata (L.) Fernald subsp. edgeworthii (Benth.) H. Ohashi & 새콩 & Sun134305 \\
\hline 208 & Astragalus sinicus L. & 자운영 & $120426-022$ \\
\hline 209 & Caragana sinica (Buc'hoz) Rehder & $\begin{array}{c}\text { 골담초 } \\
\text { (Cultivated) }\end{array}$ & LO04105323 \\
\hline 210 & Chamaecrista nomame (Makino) H. Ohashi & 차풀 & Sun170631 \\
\hline 211 & Glycine max (L.) Merr. subsp. soja (Siebold \& Zucc.) H. Ohashi & 돌콩 & 102158 \\
\hline 212 & Hylodesmum podocarpum subsp. oxyphyllum (DC.) H. Ohashi \& R. R. Mill & 도둑놈의갈고리 & Sun95019 \\
\hline 213 & Hylodesmum podocarpum var. mandshuricum (Maxim.) H. Ohashi \& R. R. Mill & 애기도둑놈의갈고리 & SKN191001054 \\
\hline 214 & Indigofera kirilowii Maxim. ex Palib. & 땅비싸리 & Sun114457 \\
\hline 215 & Kummerowia stipulacea (Maxim.) Makino & 둥근매듭풀 & Sun143021 \\
\hline 216 & Kummerowia striata (Thunb.) Schindl. & 매듭풀 & Sun92722 \\
\hline 217 & Lathyrus davidii Hance & 활량나물 & Sun153849 \\
\hline 218 & Lespedeza bicolor Turcz. & 싸리 & LO191001002 \\
\hline 219 & Lespedeza cuneata (Dum.Cours.) G. Don & 비수리 & Sun153847 \\
\hline 220 & Lespedeza cyrtobotrya Miq. & 참싸리 & Sun105761 \\
\hline 221 & Lespedeza maximowiczii C. K. Schneid. & 조록싸리 & Sun101002 \\
\hline 222 & Lespedeza maximowiczii var. tomentella Nakai & 털조록싸리 & Sun153125 \\
\hline 223 & Maackia amurensis Rupr. & 다릅나무 & LO201943 \\
\hline 224 & Pueraria lobata (Willd.) Ohwi & 칡 & SKN191001017 \\
\hline 225 & Robinia pseudoacacia L. & 아까시나무 & LO04100959 \\
\hline
\end{tabular}


Appendix 1. Continued.

\begin{tabular}{|c|c|c|c|}
\hline No. & Taxa & Korea name & Voucher number \\
\hline & Sophora flavescens Aiton & 고삼 & Sun92055 \\
\hline 227 & Trifolium pratense $\mathrm{L}$. & 붉은토끼풀 & Sun170610 \\
\hline 228 & Trifolium repens $\mathrm{L}$. & 토끼풀 & Sun65652 \\
\hline 229 & Vicia amoena Fisch. ex Ser. & 갈퀴나물 & Sun142914 \\
\hline 230 & Vicia angustifolia L. ex Reichard & 가는살갈퀴 & LO04100952 \\
\hline 231 & Vicia nipponica Matsum. & 네잎갈퀴나물 & SKN191001066 \\
\hline 232 & Vicia tetrasperma $(\mathrm{L}$.$) Schreb.$ & 얼치기완두 & LO04104759 \\
\hline 233 & Vicia unijuga A.Braun & 나비나물 & Sun64353 \\
\hline 234 & Vicia venosa (Link) Maxim. var. cuspidata Maxim. & 광릉갈퀴 & $120906-149$ \\
\hline 235 & Vicia villosa Roth & 벳지 & LO201984 \\
\hline \multirow[t]{2}{*}{236} & Vigna angularis var. nipponensis (Ohwi) Ohwi \& H. Ohashi & 새팥 & Sun174143 \\
\hline & Oxalidaceae 괭이밥과 & & \\
\hline \multirow[t]{2}{*}{237} & Oxalis corniculata $\mathrm{L}$. & 괭이밥 & LO04101019 \\
\hline & Geraniaceae 쥐손이풀과 & & \\
\hline 238 & Geranium dahuricum DC. & 산쥐손이 & 95804 \\
\hline 239 & Geranium sibiricum L. & 쥐손이풀 & Sun145424 \\
\hline 240 & Geranium thunbergii Siebold ex Lindl. \& Paxton & 이질풀 & LO04102622 \\
\hline \multirow[t]{2}{*}{241} & Geranium wilfordii Maxim. & 세잎쥐손이 & LO2019126 \\
\hline & Euphorbiaceae 대극과 & & \\
\hline 242 & Acalypha australis L. & 깨풀 & Sun91307 \\
\hline 243 & Neoshirakia japonica (Siebold \& Zucc.) Esser & 사람주나무 & Sun102714 \\
\hline \multirow[t]{2}{*}{244} & Securinega suffruticosa (Pall.) Rehder & 광대싸리 & Sun100810 \\
\hline & Rutaceae 운향과 & & \\
\hline 245 & Dictamnus dasycarpus Turcz. & 백선 & Sun103255 \\
\hline 246 & Zanthoxylum piperitum (L.) DC. & 초피나무 & Sun80045 \\
\hline \multirow[t]{2}{*}{247} & Zanthoxylum schinifolium Siebold \& Zucc. & 산초나무 & Sun84802 \\
\hline & Simaroubaceae 소태나무과 & & \\
\hline \multirow[t]{2}{*}{248} & Picrasma quassioides (D. Don) Benn. & 소태나무 & Sun101524 \\
\hline & Polygalaceae 원지과 & & \\
\hline \multirow[t]{2}{*}{249} & Polygala japonica Houtt. & 애기풀 & Sun154245 \\
\hline & Anacardiaceae 옻나무과 & & \\
\hline 250 & Rhus chinensis Mill. & 붉나무 & Sun84658 \\
\hline \multirow[t]{2}{*}{251} & Toxicodendron trichocarpum (Miq.) Kuntze & 개옻나무 & 103345 \\
\hline & Aceraceae 단풍나무과 & & \\
\hline 252 & Acer palmatum Thunb. & 단풍나무 & LOK19093002 \\
\hline 253 & Acer pictum Thunb. var. mono (Maxim.) Maxim. ex Franch. & 고로쇠나무 & Sun152438 \\
\hline 254 & Acer pseudosieboldianum (Pax) Kom. & 당단풍나무 & Sun143340 \\
\hline \multirow[t]{2}{*}{255} & Acer tataricum L. subsp. ginnala (Maxim.) Wesm. & 신나무 & LO2019135 \\
\hline & Balsaminaceae 봉선화과 & & \\
\hline 256 & Impatiens textorii Miq. & 물봉선 & Sun92941 \\
\hline
\end{tabular}


Appendix 1. Continued.

\begin{tabular}{|c|c|c|c|}
\hline No. & Taxa & Korea name & Voucher number \\
\hline & Aquifoliaceae 감탕나무과 & & \\
\hline \multirow[t]{2}{*}{257} & Ilex macropoda Miq. & 대팻집나무 & Sun100249 \\
\hline & Celastraceae 노박덩굴과 & & \\
\hline 258 & Celastrus flagellaris Rupr. & 푼지나무 & SUN143320 \\
\hline 259 & Celastrus orbiculatus Thunb. & 노박덩굴 & Sun84631 \\
\hline 260 & Euonymus alatus (Thunb.) Siebold & 화살나무 & Sun165041 \\
\hline 261 & Euonymus alatus (Thunb.) Siebold f. ciliato-dentatus (Franch. \& Sav.) Hiyama & 회잎나무 & Sun102601 \\
\hline 262 & Euonymus hamiltonianus Wall. & 참빗살나무 & Sun130647 \\
\hline 263 & Euonymus maackii Rupr. & 좁은잎참빗살나무 & LO2019188 \\
\hline 264 & Euonymus oxyphyllus Miq. & 참회나무 & LO191001011 \\
\hline 265 & Euonymus sachalinensis (F. Schmidt) Maxim. & 회나무 & Sun110630 \\
\hline \multirow[t]{2}{*}{266} & Tripterygium regelii Sprague \& Takeda & 미역줄나무 & 105424 \\
\hline & Staphyleaceae 고추나무과 & & \\
\hline \multirow[t]{2}{*}{267} & Staphylea bumalda DC. & 고추나무 & Sun145347 \\
\hline & Rhamnaceae 갈매나무과 & & \\
\hline \multirow[t]{2}{*}{270} & Rhamnus yoshinoi Makino & 짝자래나무 & Sun101002 \\
\hline & Vitaceae 포도과 & & \\
\hline 271 & Ampelopsis brevipedunculata (Maxim.) Trautv. f. ciliata (Nakai) T.B.Lee & 털개머루 & Sun104118 \\
\hline 272 & Ampelopsis heterophylla (Thunb.) Siebold \& Zucc. & 개머루 & $120907-084$ \\
\hline 273 & Parthenocissus tricuspidata (Siebold \& Zucc.) Planch. & 담쟁이덩굴 & LO04100958 \\
\hline 274 & Vitis amurensis Rupr. & 왕머루 & Sun113007 \\
\hline 275 & Vitis flexuosa Thunb. & 새머루 & Sun141723 \\
\hline \multirow[t]{2}{*}{276} & Vitis heyneana Roem. \& Schult. subsp. ficifolia (Bunge) C.L.Li & 까마귀머루 & Sun153636 \\
\hline & Tiliaceae 피나무과 & & \\
\hline \multirow[t]{2}{*}{277} & Tilia amurensis Rupr. & 피나무 & Sun95934 \\
\hline & Thymelaeaceae 팥꽃나무과 & & \\
\hline \multirow[t]{2}{*}{278} & Edgeworthia chrysantha Lindl. & $\begin{array}{l}\text { 삼지닥나무 } \\
\text { (Cultivated) }\end{array}$ & LO04100110 \\
\hline & Elaeagnaceae 보리수나무과 & & \\
\hline \multirow[t]{2}{*}{279} & Elaeagnus umbellata Thunb. & 보리수나무 & LO04101010 \\
\hline & Violaceae 제비꽃과 & & \\
\hline 280 & Viola acuminata Ledeb. & 졸방제비꽃 & Sun143330 \\
\hline 281 & Viola albida Palib. & 태백제비꽃 & Sun190410_131847 \\
\hline 282 & Viola albida Palib. var. chaerophylloides (Regel) F.Maek. ex H.Hara & 남산제비꽃 & Sun91126 \\
\hline 283 & Viola arcuata Blume & 콩제비꽃 & Sun154003 \\
\hline 284 & Viola collina Besser & 둥근털제비꽃 & LO04110924 \\
\hline 285 & Viola japonica Langsd. ex DC. & 왜제비꽃 & Sun94657 \\
\hline 286 & Viola keiskei Miq. & 잔털제비꽃 & Sun90118 \\
\hline 287 & Viola lactiflora Nakai & 흰젖제비꽃 & Sun64619 \\
\hline
\end{tabular}


Appendix 1. Continued.

\begin{tabular}{|c|c|c|c|}
\hline No. & Taxa & Korea name & Voucher number \\
\hline 288 & Viola mandshurica W. Becker & 제비꽃 & Sun90659 \\
\hline 289 & Viola orientalis (Maxim.) W. Becker & 노랑제비꽃 & Sun100701 \\
\hline 290 & Viola patrinii DC. ex Ging. & 흰제비꽃 & $120426-239$ \\
\hline 291 & Viola phalacrocarpa Maxim. & 털제비꽃 & Sun91328 \\
\hline 292 & Viola philippica Cav. & 호제비꽃 & LO04104636 \\
\hline 293 & Viola rossii Hemsl. & 고깔제비꽃 & Sun131659 \\
\hline 294 & Viola selkirkii Pursh ex Goldie & 뫼제비꽃 & Sun110227 \\
\hline \multirow[t]{2}{*}{295} & Viola tenuicornis W.Becker & 자주알록제비꽃 & Sun155200 \\
\hline & Onagraceae 바늘꽃과 & & \\
\hline \multirow[t]{2}{*}{296} & Oenothera biennis L. & 달맞이꽃 & Sun85854 \\
\hline & Haloragaceae 개미탑과 & & \\
\hline \multirow[t]{2}{*}{297} & Haloragis micrantha (Thunb.) R. Br. ex Siebold \& Zucc. & 개미탑 & SunLO191001027 \\
\hline & Alangiaceae 박쥐나무과 & & \\
\hline \multirow[t]{2}{*}{298} & Alangium platanifolium (Siebold \& Zucc.) Harms var. trilobum (Miq.) Ohwi & 박쥐나무 & Sun113507 \\
\hline & Cornaceae 충충나무과 & & \\
\hline 299 & Cornus controversa Hemsl. & 층층나무 & Sun120354 \\
\hline 300 & Cornus kousa F.Buerger ex Hance & 산딸나무 & LO04101006 \\
\hline \multirow[t]{2}{*}{301} & Cornus walteri Wangerin & 말채나무 & Sun152700 \\
\hline & Araliaceae 두릅나무과 & & \\
\hline 302 & Aralia cordata Thunb. var. continentalis (Kitag.) Y. C. Chu & 독활 & SKN191001038 \\
\hline 303 & Aralia elata (Miq.) Seem. & 두릅나무 & Sun172021 \\
\hline \multirow[t]{2}{*}{304} & Eleutherococcus sessiliflorus (Rupr. \& Maxim.) S. Y. Hu & 오갈피나무 & LO2019157 \\
\hline & Apiaceae 미나리과 & & \\
\hline \multirow[t]{2}{*}{305} & Angelica cartilaginomarginata (Makino ex Y. Yabe) Nakai & 처녀바디 & Sun155217 \\
\hline & Angelica cartilaginomarginata (Makino ex Y. Yabe) Nakai var. distans (Nakai) Kitag. & 흰바디나물 & 105130 \\
\hline 305 & Angelica dahurica (Fisch. ex Hoffm.) Benth. \& Hook.f. ex Franch. \& Sav. & 구릿대 & LO04110920 \\
\hline 306 & Angelica decursiva (Miq.) Franch. \& Sav. & 바디나물 & Sun111733 \\
\hline 307 & Angelica polymorpha Maxim. & 궁궁이 & LO04101129 \\
\hline 308 & Bupleurum komarovianum Lincz. & 시호 & Sun155006 \\
\hline 309 & Cryptotaenia japonica Hassk. & 파드득나물 & LOK19093003 \\
\hline 310 & Cymopterus melanotilingia (H.Boissieu) C. Y. Yoon & 큰참나물 & LO191001012 \\
\hline 311 & Heracleum moellendorffii Hance & 어수리 & Sun105410 \\
\hline 312 & Oenanthe javanica (Blume) DC. & 미나리 & LO04101101 \\
\hline 313 & Ostericum sieboldii (Miq.) Nakai & 묏미나리 & LO04115650 \\
\hline 314 & Peucedanum terebinthaceum (Fisch. ex Trevir.) Fisch. ex Turcz. & 기름나물 & Sun85903 \\
\hline 315 & $\begin{array}{l}\text { Peucedanum terebinthaceum (Fisch. ex Trevir.) Fisch. ex Turcz. var. deltoideum (Makino ex K. } \\
\text { Yabe) Makino }\end{array}$ & 산기름나물 & Sun100250 \\
\hline 316 & Sanicula chinensis Bunge & 참반디 & Sun102458 \\
\hline 317 & Sium ninsi L. & 감자개발나물 & SKN191001057 \\
\hline 318 & Torilis japonica (Houtt.) DC. & 사상자 & Sun151005 \\
\hline
\end{tabular}


Appendix 1. Continued.

\begin{tabular}{|c|c|c|c|}
\hline No. & Taxa & Korea name & Voucher number \\
\hline \multirow[t]{2}{*}{319} & Torilis scabra (Thunb.) DC. & 개사상자 & LO04105729 \\
\hline & Pyrolaceae 진달래과 & & \\
\hline 320 & Chimaphila japonica Miq. & 매화노루발 & Sun155034 \\
\hline 321 & Pyrola japonica Klenze ex Alef. & 노루발 & Sun103720 \\
\hline 322 & Rhododendron mucronulatum Turcz. & 진달래 & Sun20190320_004 \\
\hline 323 & Rhododendron schlippenbachii Maxim. & 철쭉 & Sun100126 \\
\hline 324 & Rhododendron yedoense Maxim. f. poukhanense (H. Lév.) Sugim. ex T. Yamaz. & 산철쭉 & Sun100826 \\
\hline \multirow[t]{2}{*}{325} & Vaccinium hirtum Thunb. var. koreanum (Nakai) Kitam. & 산앵도나무 & LO04100239 \\
\hline & Primulaceae 앵초과 & & \\
\hline 326 & Androsace umbellata (Lour.) Merr. & 봄맞이 & Sun153628 \\
\hline 327 & Lysimachia clethroides Duby & 큰까치수염 & Sun111250 \\
\hline 328 & Lysimachia japonica Thunb. & 좀가지풀 & Sun182003 \\
\hline \multirow[t]{2}{*}{329} & Primula sieboldii E.Morren & 앵초 & Sun111408 \\
\hline & Ebenaceae 감나무과 & & \\
\hline \multirow[t]{2}{*}{330} & Diospyros lotus L. & 고욤나무 & Sun100211 \\
\hline & Styracaceae 때죽나무과 & & \\
\hline \multirow[t]{2}{*}{331} & Styrax japonicus Siebold \& Zucc. & 때죽나무 & Sun101010 \\
\hline & Symplocaceae 노린재나무과 & & \\
\hline 332 & Symplocos sawafutagi Nagam. & 노린재나무 & Sun85751 \\
\hline \multirow[t]{2}{*}{333} & Symplocos tanakana Nakai & 검노린재나무 & Sun112040 \\
\hline & Oleaceae 물푸레나무과 & & \\
\hline 334 & Forsythia koreana (Rehder) Nakai & $\begin{array}{c}\text { 개나리 } \\
\text { (Cultivated) }\end{array}$ & Sun154243 \\
\hline 335 & Fraxinus rhynchophylla Hance & 물푸레나무 & Sun82221 \\
\hline 336 & Fraxinus sieboldiana Blume & 쇠물푸레나무 & Sun173922 \\
\hline 337 & Ligustrum japonicum Thunb. & 광나무 & Sun151002 \\
\hline 338 & Ligustrum obtusifolium Siebold \& Zucc. & 쥐똥나무 & Sun154434 \\
\hline \multirow[t]{2}{*}{339} & Syringa pubescens Turcz. subsp. patula (Palib.) M. C. Chang \& X. L. Chen & 털개회나무 & Sun100622 \\
\hline & Gentianaceae 용담과 & & \\
\hline 340 & Gentiana scabra Bunge & 용담 & Sun104513 \\
\hline 341 & Gentiana zollingeri Fawc. & 큰구슬붕이 & Sun94424 \\
\hline 342 & Swertia japonica (Schult.) Makino & 쓴풀 & LOK190930042 \\
\hline \multirow[t]{2}{*}{343} & Swertia pseudochinensis H.Hara & 자주쓴풀 & LOK190930035 \\
\hline & Asclepiadaceae 협죽도과 & & \\
\hline 344 & Cynanchum ascyrifolium (Franch. \& Sav.) Matsum. & 민백미꽃 & LO201973 \\
\hline 345 & Cynanchum paniculatum (Bunge) Kitag. ex H.Hara & 산해박 & Sun113656 \\
\hline \multirow[t]{2}{*}{346} & Metaplexis japonica (Thunb.) Makino & 박주가리 & Sun170630 \\
\hline & Rubiaceae 꼭두서니과 & & \\
\hline 347 & Galium bungei Steud. var. trachyspermum (A.Gray) Cufod. & 네잎갈퀴 & Sun133736 \\
\hline 348 & Galium dahuricum Turcz. ex Ledeb. & 큰잎갈퀴 & Sun160049 \\
\hline
\end{tabular}


Appendix 1. Continued.

\begin{tabular}{|c|c|c|c|}
\hline No. & Taxa & Korea name & Voucher number \\
\hline 349 & Galium gracilens (A. Gray) Makino & 좀네잎갈퀴 & Sun144849 \\
\hline 350 & Galium kinuta Nakai \& H. Hara & 검은개선갈퀴 & Sun111743 \\
\hline 351 & Galium pogonanthum Franch. \& Sav. & 산갈퀴 & Sun163528 \\
\hline 352 & Galium spurium $\mathrm{L}$. & 갈퀴덩굴 & LO04101057 \\
\hline 353 & Galium tokyoense Makino & 흰갈퀴 & LO2019233 \\
\hline 354 & Galium verum $\mathrm{L}$. & 솔나물 & LO04101013 \\
\hline 355 & Paederia foetida $\mathrm{L}$. & 계요등 & LOK190930055 \\
\hline \multirow[t]{2}{*}{356} & Rubia argyi (H. Lév. \& Vaniot) H. Hara ex Lauener & 꼭두서니 & Sun85614 \\
\hline & Convolvulaceae 메꽃과 & & \\
\hline 357 & Calystegia pubescens Lindl. & 메꽃 & Sun150733 \\
\hline 358 & Cuscuta japonica Choisy & 새삼 & Sun144005 \\
\hline \multirow[t]{2}{*}{359} & Ipomoea hederacea Jacq. & 미국나팔꽃 & SKN191001081 \\
\hline & Boraginaceae 지치과 & & \\
\hline 360 & Trigonotis icumae (Maxim.) Makino & 덩굴꽃마리 & Sun135443 \\
\hline 361 & Trigonotis peduncularis (Trevis.) Benth. ex Baker \& S.Moore & 꽃마리 & Sun190320_151944 \\
\hline \multirow[t]{2}{*}{362} & Trigonotis radicans (Turcz.) Steven var. sericea (Maxim.) H.Hara & 참꽃마리 & 100134 \\
\hline & Verbenaceae 마편초과 & & \\
\hline 363 & Callicarpa japonica Thunb. & 작살나무 & Sun134725 \\
\hline \multirow[t]{2}{*}{364} & Clerodendrum trichotomum Thunb. & 누리장나무 & Sun173306 \\
\hline & Lamiaceae 꿀풀과 & & \\
\hline 365 & Agastache rugosa (Fisch. \& C. A. Mey.) Kuntze & 배초향 & Sun173306 \\
\hline 366 & Ajuga decumbens Thunb. & 금창초 & Sun152955 \\
\hline 367 & Clinopodium chinense (Benth.) Kuntze var. parviflorum (Kudô) H. Hara & 층층이꽃 & LO04112033 \\
\hline 368 & Clinopodium chinense (Benth.) Kuntze var. shibetchense (H. Lév.) Koidz. & 산층층이 & LO04102828 \\
\hline 369 & Clinopodium micranthum (Regel) H.Hara & 두메층층이 & 101219 \\
\hline 370 & Elsholtzia ciliata (Thunb.) Hyl. & 향유 & Sun85928 \\
\hline 371 & Elsholtzia splendens Nakai ex F.Maek. & 꽃향유 & LO191001017 \\
\hline 372 & Galeopsis bifida Boenn. & 털향유 & LEE0709 \\
\hline 373 & Isodon excisus (Maxim.) Kudô & 오리방풀 & Sun130542 \\
\hline 374 & Isodon inflexus (Thunb.) Kudô & 산박하 & LO04102847 \\
\hline 375 & Isodon japonicus (Burm.f.) H. Hara & 방아풀 & LO191001009 \\
\hline 376 & Lamium album L. subsp. barbatum (Siebold \& Zucc.) Mennema & 광대수염 & Sun141010 \\
\hline 377 & Lamium amplexicaule $\mathrm{L}$. & 광대나물 & Sun190320_151958 \\
\hline 378 & Leonurus japonicus Houtt. & 익모초 & LO04101009 \\
\hline 379 & Leonurus macranthus Maxim. & 송장풀 & Sun101442 \\
\hline 380 & Lycopus charkeviczii Prob. & 산쉽싸리 & SKN191001055 \\
\hline 381 & Lycopus lucidus Turcz. ex Benth. & 쉽싸리 & Sun93118 \\
\hline 382 & Lycopus maackianus (Maxim. ex Herder) Makino & 애기쉽싸리 & $120907-028$ \\
\hline 383 & Meehania urticifolia (Miq.) Makino & 벌깨덩굴 & Sun142944 \\
\hline 384 & Mosla dianthera (Buch.-Ham. ex Roxb.) Maxim. & 쥐깨풀 & LOK190930048 \\
\hline
\end{tabular}


Appendix 1. Continued.

\begin{tabular}{|c|c|c|c|}
\hline No. & Taxa & Korea name & Voucher number \\
\hline 385 & Mosla japonica (Benth. ex Oliv.) Maxim. & 산들깨 & LEE1910 \\
\hline 386 & Mosla scabra (Thunb.) C. Y. Wu \& H. W. L & 들깨풀 & LO191001025 \\
\hline 387 & Perilla frutescens (L.) Britton var. crispa (Thunb.) H. Deane & 소엽 & LOK190930016 \\
\hline 388 & Phlomis umbrosa Turcz. & 속단 & Sun130520 \\
\hline 389 & Prunella vulgaris L. subsp. asiatica (Nakai) H. Hara & 꿀풀 & Sun190320_140510 \\
\hline 390 & Prunella vulgaris L. var. aleutica Fernald & 두메꿀풀 & Sun104705 \\
\hline 391 & Salvia plebeia $\mathrm{R} . \mathrm{Br}$. & 배암차즈기 & Sun145750 \\
\hline 392 & Scutellaria indica $\mathrm{L}$. & 골무꽃 & Sun160650 \\
\hline 393 & Scutellaria pekinensis Maxim. var. transitra (Makino) H. Hara & 산골무꽃 & Sun115140 \\
\hline 394 & Stachys riederi Cham. var. japonica (Miq.) H. Hara & 석잠풀 & 102815 \\
\hline \multirow[t]{2}{*}{395} & Teucrium viscidum Blume var. miquelianum (Maxim.) H. Hara & 덩굴곽향 & Sun102225 \\
\hline & Solanaceae 가지과 & & \\
\hline 396 & Lycium chinense Mill. & 구기자나무 & LO04101158 \\
\hline 397 & Physaliastrum echinatum (Yatabe) Makino & 가시꽈리 & Sun101515 \\
\hline 398 & Solanum nigrum L. & 까마중 & Sun142520 \\
\hline \multirow[t]{2}{*}{399} & Solanum lyratum Thunb. & 배풍등 & LO191001045 \\
\hline & Scrophulariaceae 현삼과 & & \\
\hline 400 & Euphrasia maximowiczii Wettst. ex Palib. & 앉은좁쌀풀 & Lee1911 \\
\hline 401 & Mazus pumilus (Burm.f.) Steenis & 주름잎 & Sun145021 \\
\hline 402 & Melampyrum roseum Maxim. & 꽃며느리밥풀 & Sun113411 \\
\hline 403 & Melampyrum roseum Maxim. var. japonicum Franch. \& Sav. & 수염며느리밥풀 & LO191001007 \\
\hline 404 & Melampyrum roseum Maxim. var. ovalifolium (Nakai) Nakai ex Beauverd & 알며느리밥풀 & Sun92728 \\
\hline 405 & Paulownia coreana Uyeki & 오동나무 & LO04101007 \\
\hline 406 & Phtheirospermum japonicum (Thunb.) Kanitz & 나도송이풀 & Sun144042 \\
\hline 407 & Pseudolysimachion linariifolium (Pall. ex Link) Holub & 꼬리풀 & Sun125858 \\
\hline 408 & Veronica arvensis $\mathrm{L}$. & 선개불알풀 & LO2019123 \\
\hline 409 & Veronica hederifolia L. & 눈개불알풀 & Sun72725 \\
\hline \multirow[t]{2}{*}{410} & Veronica persica Poir. & 큰개불알풀 & Sun190320_152045 \\
\hline & Bignoniaceae 능소화과 & & \\
\hline \multirow[t]{2}{*}{411} & Catalpa ovata G. Don & 개오동 & 155217 \\
\hline & Acanthaceae 쥐꼬리망초과 & & \\
\hline \multirow[t]{2}{*}{412} & Justicia procumbens L. & 쥐꼬리망초 & SKN191001095 \\
\hline & Phrymaceae 파리풀과 & & \\
\hline \multirow[t]{2}{*}{413} & Phryma leptostachya L. var. oblongifolia (Koidz.) Honda & 파리풀 & Sun93503 \\
\hline & Plantaginaceae 질경이과 & & \\
\hline \multirow[t]{2}{*}{414} & Plantago asiatica $\mathrm{L}$. & 질경이 & Sun71506 \\
\hline & Caprifoliaceae 인동과 & & \\
\hline 415 & Lonicera harae Makino & 길마가지나무 & Sun175922 \\
\hline 416 & Lonicera japonica Thunb. & 인동덩굴 & LO04101025 \\
\hline 417 & Sambucus racemosa L. subsp. kamtschatica (E. Wolf) Hultén & 지렁쿠나무 & Sun190320_142953 \\
\hline
\end{tabular}


Appendix 1. Continued.

\begin{tabular}{|c|c|c|c|}
\hline No. & Taxa & Korea name & Voucher number \\
\hline 418 & Viburnum dilatatum Thunb. & 가막살나무 & LO04100219 \\
\hline 419 & Viburnum erosum Thunb. & 덜뀡나무 & LO04101149 \\
\hline 420 & Viburnum opulus L. var. calvescens (Rehder) H. Hara & 백당나무 & Sun93444 \\
\hline 421 & Weigela florida (Bunge) A. DC. & 붉은병꽃나무 & Sun85731 \\
\hline 422 & Weigela hortensis (Siebold \& Zucc.) K. Koch & 골병꽃나무 & Sun83040 \\
\hline \multirow[t]{2}{*}{423} & Weigela subsessilis (Nakai) L. H. Bailey & 병꽃나무 & Sun85111 \\
\hline & Adoxaceae 연복초과 & & \\
\hline \multirow[t]{2}{*}{424} & Adoxa moschatellina $\mathrm{L}$. & 연복초 & Sun142819 \\
\hline & Valerianaceae 마타리과 & & \\
\hline 425 & Patrinia scabiosifolia Fisch. ex Trevir. & 마타리 & Sun 85120 \\
\hline 426 & Patrinia villosa (Thunb.) Juss. & 뚝갈 & 92835 \\
\hline \multirow[t]{2}{*}{427} & Valeriana fauriei Briq. & 쥐오줌풀 & Sun72038 \\
\hline & Campanulaceae 초롱꽃과 & & \\
\hline 428 & Adenophora triphylla (Thunb.) A. DC. & 층층잔대 & Sun90344 \\
\hline 429 & Adenophora triphylla (Thunb.) A. DC. var. japonica (Regel) H. Hara & 잔대 & Sun072544 \\
\hline 430 & Codonopsis lanceolata (Siebold \& Zucc.) Benth. \& Hook.f. ex Trautv. & 더덕 & Sun123506 \\
\hline \multirow[t]{2}{*}{431} & Platycodon grandiflorus (Jacq.) A. DC. & 도라지 & 105126 \\
\hline & Asteraceae 국화과 & & \\
\hline 432 & Achillea millefolium $\mathrm{L}$. & 서양톱풀 & Sun70300 \\
\hline 433 & Ainsliaea acerifolia Sch.Bip. & 단풍취 & Sun111741 \\
\hline 434 & Ambrosia artemisiifolia $\mathrm{L}$. & 돼지풀 & Sun90424 \\
\hline 435 & Artemisia capillaris Thunb. & 사철쑥 & SKN191001019 \\
\hline 436 & Artemisia codonocephala Diels & 참쑥 & LO04105344 \\
\hline 437 & Artemisia indica Willd. & 丛 & Sun81328 \\
\hline 438 & Artemisia japonica Thunb. & 제비쑥 & Sun110026 \\
\hline 439 & Artemisia keiskeana Miq. & 맑은대쑥 & Sun92018 \\
\hline 440 & Artemisia sacrorum Ledeb. var. iwayomogi (Kitam.) M. S. Park \& G. Y. Chung & 더위지기 & Sun103120 \\
\hline 441 & Aster ageratoides Turcz. & 까실쑥부쟁이 & Sun124000 \\
\hline 442 & Aster hispidus Thunb. & 갯쑥부쟁이 & Sun170311 \\
\hline 443 & Aster incisus Fisch. & 가새쑥부쟁이 & SKN191001011 \\
\hline 444 & Aster scaber Thunb. & 참취 & Sun85620 \\
\hline 445 & Aster yomena (Kitam.) Honda & 쑥부쟁이 & Sun163021 \\
\hline 446 & Atractylodes ovata (Thunb.) DC. & 삽주 & Sun103151 \\
\hline 447 & Bidens bipinnata L. & 도깨비바늘 & Sun153846 \\
\hline 448 & Bidens biternata (Lour.) Merr. \& Sherff ex Sherff & 털도깨비바늘 & 120906-094 \\
\hline 449 & Bidens frondosa $\mathrm{L}$. & 미국가막사리 & SKN191001087 \\
\hline 450 & Bidens pilosa $\mathrm{L}$. & 울산도깨비바늘 & LO191001043 \\
\hline 451 & Bidens tripartita $\mathrm{L}$. & 가막사리 & Sun170632 \\
\hline 452 & Carpesium abrotanoides $\mathrm{L}$. & 담배풀 & 85252 \\
\hline 453 & Carpesium divaricatum Siebold \& Zucc. & 긴담배풀 & Sun131310 \\
\hline
\end{tabular}


Appendix 1. Continued.

\begin{tabular}{|c|c|c|c|}
\hline No. & Taxa & Korea name & Voucher number \\
\hline & Chrysanthemum boreale (Makino) Makino & 산국 & LOK19093009 \\
\hline 455 & Chrysanthemum indicum $\mathrm{L}$. & 감국 & 190320_151612 \\
\hline 456 & Chrysanthemum zawadskii Herbich & 산구절초 & Sun100154 \\
\hline 457 & Chrysanthemum zawadskii Herbich var. latilobum (Maxim.) Kitam. & 구절초 & LO04100137 \\
\hline 458 & Cirsium japonicum Fisch. ex DC. var. maackii (Maxim.) Matsum. & 엉겅퀴 & LO04115845 \\
\hline 459 & Cirsium setidens (Dunn) Nakai & 고려엉겅퀴 & Sun131059 \\
\hline 460 & Conyza canadensis (L.) Cronquist & 망초 & Sun85022 \\
\hline 461 & Coreopsis lanceolata $\mathrm{L}$. & $\begin{array}{c}\text { 큰금계국 } \\
\text { (Cultivated) }\end{array}$ & Sun90601 \\
\hline 462 & Cosmos bipinnatus Cav. & $\begin{array}{c}\text { 코스모스 } \\
\text { (Cultivated) }\end{array}$ & SKN191001044 \\
\hline 463 & Crassocephalum crepidioides (Benth.) S.Moore & 주홍서나물 & Sun142819 \\
\hline 464 & Crepidiastrum chelidoniifolium (Makino) J. H. Pak \& Kawano & 까치고들빼기 & LO191001023 \\
\hline 465 & Crepidiastrum denticulatum (Houtt.) J. H. Pak \& Kawano & 이고들빼기 & LOK190930040 \\
\hline 466 & Crepidiastrum sonchifolium (Maxim.) J. H. Pak \& Kawano & 고들빼기 & Sun70333 \\
\hline 467 & Erechtites hieraciifolius (L.) Raf. ex DC. & 붉은서나물 & Sun91321 \\
\hline 468 & Erigeron annuus (L.) Pers. & 개망초 & LO04100930 \\
\hline 469 & Eupatorium japonicum Thunb. & 등골나물 & Sun84747 \\
\hline 470 & Eupatorium lindleyanum DC. & 골등골나물 & SKN191001024 \\
\hline 471 & Galinsoga ciliata (Raf.) S. F. Blake & 털별꽃아재비 & SKN191001097 \\
\hline 472 & Hemistepta lyrata (Bunge) Bunge & 지칭개 & Sun170114 \\
\hline 473 & Hieracium umbellatum L. & 조밥나물 & Sun113640 \\
\hline 474 & Inula japonica Thunb. & 금불초 & 101658 \\
\hline 475 & Inula linariifolia Turcz. & 가는금불초 & 101658 \\
\hline 476 & Inula salicina $\mathrm{L}$. & 버들금불초 & Sun145813 \\
\hline 477 & Ixeridium dentatum (Thunb.) Tzvelev & 씀바귀 & Sun153143 \\
\hline 478 & Ixeridium dentatum (Thunb.) Tzvelev f. albiflora (Makino) H. Hara & 흰씀바귀 & Sun94044 \\
\hline 479 & Ixeris chinensis (Thunb.) Nakai & 노랑선씀바귀 & Sun70411 \\
\hline 480 & Ixeris polycephala Cass. & 벌씀바귀 & LO04100947 \\
\hline 481 & Ixeris strigosa (H. Lév. \& Vaniot) J. H. Pak \& Kawano & 선씀바귀 & Sun152758 \\
\hline 482 & Lactuca indica $\mathrm{L}$. & 왕고들빼기 & LO04103143 \\
\hline & Lactuca raddeana Maxim. & 산씀바귀 & LO2019110 \\
\hline 484 & Lactuca serriola L. & 가시상추 & Sun144715 \\
\hline 485 & Leibnitzia anandria (L.) Turcz. & 솜나물 & Sun72433 \\
\hline & Ligularia fischeri (Ledeb.) Turcz. & 곰취 & Sun131002 \\
\hline & Petasites japonicus (Siebold \& Zucc.) Maxim. & 머위 & Sun140229 \\
\hline & Picris hieracioides L. subsp.japonica (Thunb.) Hand.-Mazz. & 쇠서나물 & 112045 \\
\hline & Pseudognaphalium affine (D. Don) Anderb. & 떡쑥 & LO04100132 \\
\hline & Saussurea gracilis Maxim. & 은분취 & Sun111640 \\
\hline & Saussurea maximowiczii Herder & 버들분취 & Sun124116 \\
\hline
\end{tabular}


Appendix 1. Continued.

\begin{tabular}{|c|c|c|c|}
\hline No. & Taxa & Korea name & Voucher number \\
\hline & Saussurea odontolepis (Herder) Sch. Bip. ex Maxim. & 빗살서덜취 & 120907-094 \\
\hline 493 & Senecio vulgaris $\mathrm{L}$. & 개쑥갓 & Sun153311 \\
\hline 494 & Serratula coronata L. subsp. insularis (Iljin) Kitam. & 산비장이 & Sun111135 \\
\hline 495 & Sigesbeckia glabrescens (Makino) Makino & 진득찰 & SKN191001073 \\
\hline 496 & Sigesbeckia orientalis L. subsp. pubescens (Makino) H.Koyama & 털진득찰 & LO191001013 \\
\hline 497 & Solidago virgaurea L. subsp.`a asiatica Kitam. ex H.Hara & 미역취 & 105621 \\
\hline 498 & Sonchus brachyotus DC. & 사데풀 & Sun131520 \\
\hline 499 & Sonchus oleraceus L. & 방가지똥 & Sun150748 \\
\hline 500 & Symphyotrichum pilosum (Willd.) G. L. Nesom & 미국쑥부쟁이 & Sun85258 \\
\hline 501 & Synurus deltoides (Aiton) Nakai & 수리취 & Sun110013 \\
\hline 502 & Tagetes patula $\mathrm{L}$. & $\begin{array}{c}\text { 만수국 } \\
\text { (Cultivated) }\end{array}$ & LOK19093004 \\
\hline 503 & Taraxacum coreanum Nakai & 흰민들레 & Sun150423 \\
\hline 504 & Taraxacum officinale $\mathrm{F}$. H. Wigg. & 서양민들레 & LO04100133 \\
\hline 505 & Taraxacum platycarpum Dahlst. & 민들레 & Sun140125 \\
\hline 506 & Tephroseris kirilowii (Turcz. ex DC.) Holub & 솜방망이 & Sun190320_151314 \\
\hline \multirow[t]{2}{*}{507} & Youngia japonica (L.) DC. & 뽀리뱅이 & LO04105544 \\
\hline & Liliaceae 백합과 & & \\
\hline 508 & Allium macrostemon Bunge & 산달래 & Sun113609 \\
\hline 509 & Allium monanthum Maxim. & 달래 & Sun132531 \\
\hline 510 & Allium sacculiferum Maxim. & 참산부추 & LOK190930010 \\
\hline 511 & Allium thunbergii G. Don & 산부추 & 120935 \\
\hline 512 & Asparagus schoberioides Kunth & 비짜루 & Sun153940 \\
\hline 513 & Barnardia japonica (Thunb.) Schult. f. & 무릇 & Sun190320_140310 \\
\hline 514 & Convallaria keiskei Miq. & 은방울꽃 & Sun105820 \\
\hline 515 & Disporum smilacinum A. Gray & 애기나리 & LO04100200 \\
\hline 516 & Disporum viridescens (Maxim.) Nakai & 큰애기나리 & Sun83106 \\
\hline 517 & Erythronium japonicum Decne. & 얼레지 & Sun132337 \\
\hline 518 & Hemerocallis fulva (L.) L. & 원추리 & Sun112036 \\
\hline 519 & Hemerocallis fulva (L.) L. f. kwanso (Regel) Kitam. & 왕원추리 & Sun91014 \\
\hline 520 & Hemerocallis hakuunensis Nakai & 백운산원추리 & Sun110451 \\
\hline 521 & Hosta capitata (Koidz.) Nakai & 일월비비추 & Sun95341 \\
\hline 522 & Hosta clausa Nakai & 주걱비비추 & LO2019189 \\
\hline 523 & Hosta minor (Baker) Nakai & 좀비비추 & Sun131314 \\
\hline & Lilium amabile Palib. & 털중나리 & Sun90230 \\
\hline & Lilium distichum Nakai ex Kamib. & 말나리 & LO201955 \\
\hline 526 & Lilium lancifolium Thunb. & 참나리 & LO04101001 \\
\hline 527 & Lilium tsingtauense Gilg & 하늘말나리 & Sun111256 \\
\hline 528 & Liriope spicata (Thunb.) Lour. & 개맥문동 & LOK19093005 \\
\hline & Maianthemum japonicum (A. Gray) LaFrankie & 풀솜대 & Sun144737 \\
\hline
\end{tabular}


Appendix 1. Continued.

\begin{tabular}{|c|c|c|c|}
\hline No. & Taxa & Korea name & Voucher number \\
\hline 530 & Polygonatum involucratum (Franch. \& Sav.) Maxim. & 용둥굴레 & $120426-008$ \\
\hline 531 & Polygonatum lasianthum Maxim. & 죽대 & 2019190 \\
\hline 532 & Polygonatum odoratum (Mill.) Druce var. pluriflorum (Miq.) Ohwi & 둥굴레 & Sun81654 \\
\hline 533 & Smilax china $\mathrm{L}$. & 청미래덩굴 & Sun154444 \\
\hline 534 & Smilax nipponica Miq. & 선밀나물 & Sun75247 \\
\hline 535 & Smilax riparia A.DC. & 밀나물 & Sun114454 \\
\hline 536 & Smilax sieboldii Miq. & 청가시덩굴 & Sun172534 \\
\hline 537 & Smilax sieboldii Miq. f. inermis (Nakai ex T. Mori) H.Hara & 민청가시덩굴 & Sun155217 \\
\hline 538 & Tulipa edulis (Miq.) Baker & 산자고 & Sun145708 \\
\hline \multirow[t]{2}{*}{539} & Veratrum maackii Regel var. parviflorum (Maxim. ex Miq.) H. Hara & 파란여로 & Sun130845 \\
\hline & Dioscoreaceae 마과 & & \\
\hline 540 & Dioscorea japonica Thunb. & 참마 & Sun153850 \\
\hline 541 & Dioscorea nipponica Makino & 부채마 & Sun105634 \\
\hline \multirow[t]{2}{*}{542} & Dioscorea polystachya Turcz. & 마 & Sun91511 \\
\hline & Iridaceae 붓꽃과 & & \\
\hline 543 & Iris minutoaurea Makino & 금붓꽃 & $120426-128$ \\
\hline \multirow[t]{2}{*}{544} & Iris sanguinea Donn ex Hornem. & 붓꽃 & Sun172954 \\
\hline & Juncaceae 골풀과 & & \\
\hline 545 & Juncus decipiens (Buchenau) Nakai & 골풀 & Sun65900 \\
\hline 546 & Juncus papillosus Franch. \& Sav. & 청비녀골풀 & LO191001030 \\
\hline 547 & Juncus tenuis Willd. & 길골풀 & LO191001001 \\
\hline 548 & Juncus wallichianus J. Gay ex Laharpe & 눈비녀골풀 & Sun93404 \\
\hline \multirow[t]{2}{*}{549} & Luzula capitata (Miq. ex Franch. \& Sav.) Kom. & 꿩의밥 & Sun92315 \\
\hline & Commelinaceae 닭의장풀과 & & \\
\hline 550 & Commelina communis L. & 닭의장풀 & SKN191001077 \\
\hline \multirow[t]{2}{*}{551} & Tradescantia reflexa Raf. & 자주달개비 & Sun91814 \\
\hline & Eriocaulaceae 곡정초과 & & \\
\hline 552 & Eriocaulon atrum Nakai & 검은곡정초 & LOK190930013 \\
\hline \multirow[t]{2}{*}{553} & Eriocaulon decemflorum Maxim. & 좀개수염 & LOK190930012 \\
\hline & Poaceae 벼과 & & \\
\hline 554 & Alopecurus aequalis Sobol. & 뚝새풀 & LO04101213 \\
\hline 555 & Arundinella hirta (Thunb.) Tanaka var. ciliata (Thunb.) Koidz. & 새 & Sun85132 \\
\hline 556 & Bromus japonicus Thunb. & 참새귀리 & Sun151004 \\
\hline 557 & Calamagrostis arundinacea (L.) Roth & 실새풀 & SKN191001020 \\
\hline 558 & Cymbopogon goeringii (Steud.) A. Camus & 개솔새 & LOK190930021 \\
\hline 559 & Dactylis glomerata $\mathrm{L}$. & 오리새 & Sun150203 \\
\hline 560 & Digitaria ciliaris (Retz.) Koeler & 바랭이 & Sun153845 \\
\hline 561 & Digitaria radicosa (J.Presl) Miq. & 좀바랭이 & LO191001022 \\
\hline 562 & Echinochloa crus-galli (L.) P.Beauv. & 돌피 & SKN191001071 \\
\hline 563 & Elymus ciliaris (Trin. ex Bunge) Tzvelev & 속털개밀 & 170113 \\
\hline
\end{tabular}


Appendix 1. Continued.

\begin{tabular}{|c|c|c|c|}
\hline No. & Taxa & Korea name & Voucher number \\
\hline 564 & Eragrostis ferruginea (Thunb.) P. Beauv. & 그령 & Sun85038 \\
\hline 565 & Eragrostis multicaulis Steud. & 비노리 & Sun170110 \\
\hline 566 & Eriochloa villosa (Thunb.) Kunth & 나도개피 & 93555 \\
\hline 567 & Festuca arundinacea Schreb. & 큰김의털 & Sun71636 \\
\hline 568 & Festuca rubra L. & 왕김의털 & Sun64621 \\
\hline 569 & Hierochloe odorata (L.) P. Beauv. & 향모 & Sun152623 \\
\hline 570 & Microstegium vimineum (Trin.) A. Camus var. polystachyum (Franch. \& Sav.) Ohwi & 큰듬성이삭새 & LO191001029 \\
\hline 571 & Miscanthus sinensis Andersson & 참억새 & 090656 \\
\hline 572 & Miscanthus sinensis Andersson var. purpurascens (Andersson) Matsum. & 억새 & LO04104058 \\
\hline 573 & Molinia japonica Hack. & 진퍼리새 & LO191001039 \\
\hline 574 & Oplismenus undulatifolius (Ard.) P. Beauv. & 주름조개풀 & Sun85326 \\
\hline 575 & Panicum bisulcatum Thunb. & 개기장 & LO191001020 \\
\hline 576 & Paspalum thunbergii Kunth ex Steud. & 참새피 & $120906-223$ \\
\hline 577 & Pennisetum alopecuroides (L.) Spreng. & 수크령 & SKN191001084 \\
\hline 578 & Phyllostachys nigra (Lodd. ex Lindl.) Munro var. henonis (Mitford) Stapf ex Rendle & 솜대 & LO04100611 \\
\hline 579 & Poa annua L. & 새포아풀 & LO04101957 \\
\hline 580 & Poa sphondylodes Trin. & 포아풀 & Sun71853 \\
\hline 581 & Sacciolepis indica (L.) Chase var. oryzetorum (Makino) Ohwi & 물뚝새 & LOK190930015 \\
\hline 582 & Sasa borealis (Hack.) Makino \& Shibata & 조릿대 & Sun190320_133931 \\
\hline 583 & Setaria pumila (Poir.) Roem. \& Schult. & 금강아지풀 & LO191001018 \\
\hline 584 & Setaria viridis (L.) P. Beauv. & 강아지풀 & SKN191001023 \\
\hline 585 & Spodiopogon sibiricus Trin. & 큰기름새 & LO191001033 \\
\hline 586 & Themeda triandra Forssk. & 솔새 & Sun101440 \\
\hline \multirow[t]{2}{*}{587} & Zoysia japonica Steud. & 잔디 & $120614-140$ \\
\hline & Araceae 천남성과 & & \\
\hline 588 & Arisaema amurense Maxim. f. serratum (Nakai) Kitag. & 천남성 & Sun110632 \\
\hline \multirow[t]{2}{*}{589} & Pinellia ternata (Thunb.) Makino & 반하 & Sun92003 \\
\hline & Cyperaceae 사초과 & & \\
\hline 590 & Carex biwensis Franch. & 솔잎사초 & Sun92624 \\
\hline 591 & Carex breviculmis $\mathrm{R} . \mathrm{Br}$. & 청사초 & Sun92924 \\
\hline 592 & Carex ciliato-marginata Nakai & 털대사초 & LO2019217 \\
\hline 593 & Carex dimorpholepis Steud. & 이삭사초 & Sun155217 \\
\hline 594 & Carex forficula Franch. \& Sav. & 산뚝사초 & LO04110904 \\
\hline 595 & Carex fusanensis Ohwi & 부산사초 & Sun120452 \\
\hline 596 & Carex humilis Leyss. var. nana (H. Lév. \& Vaniot) Ohwi & 가는잎그늘사초 & Sun91925 \\
\hline 597 & Carex jaluensis Kom. & 참삿갓사초 & Sun141010 \\
\hline 598 & Carex japonica Thunb. & 개찌버리사초 & Sun132318 \\
\hline 599 & Carex kamagariensis K. Okamoto & 좀목포사초 & Sun110634 \\
\hline 600 & Carex laevissima Nakai & 애괭이사초 & Sun72039 \\
\hline 601 & Carex lanceolata Boott & 그늘사초 & Sun190320_152640 \\
\hline
\end{tabular}


Appendix 1. Continued.

\begin{tabular}{|c|c|c|c|}
\hline No. & Taxa & Korea name & Voucher number \\
\hline & Carex leiorhyncha C. A. Mey. & 산괭이사초 & $120614-044$ \\
\hline 603 & Carex maximowiczii Miq. & 왕비늘사초 & Sun123518 \\
\hline 604 & Carex miyabei Franch. & 융단사초 & LO2019164 \\
\hline 605 & Carex okamotoi Ohwi & 지리대사초 & \\
\hline 606 & Carex polyschoena H. Lév. \& Vaniot & 가지청사초 & Sun91926 \\
\hline 607 & Carex sabynensis Less. ex Kunth & 실청사초 & Sun93448 \\
\hline 608 & Carex siderosticta Hance & 대사초 & Sun111938 \\
\hline 609 & Cyperus difformis $\mathrm{L}$. & 알방동사니 & Sun151130 \\
\hline 610 & Cyperus iria $\mathrm{L}$. & 참방동사니 & $120906-236$ \\
\hline 611 & Cyperus microiria Steud. & 금방동사니 & Sun153844 \\
\hline 612 & Cyperus orthostachyus Franch. \& Sav. & 쇠방동사니 & LOK190930017 \\
\hline 613 & Eleocharis congesta D.Don & 바늘골 & Sun115506 \\
\hline 614 & Eleocharis mamillata L.f. var. cyclocarpa Kitag. & 물꼬챙이골 & Sun65724 \\
\hline 615 & Fimbristylis littoralis Gaudich. & 바람하늘지기 & 153912 \\
\hline 616 & Fimbristylis stauntonii Debeaux \& Franch. & 밭하늘지기 & Sun150946 \\
\hline 617 & Kyllinga brevifolia Rottb. var. leiolepis (Franch. \& Sav.) H.Hara & 파대가리 & Sun150914 \\
\hline 618 & Pycreus sanguinolentus (Vahl) Nees & 방동사니대가리 & Sun143332 \\
\hline 619 & Schoenoplectiella hotarui (Ohwi) J. Jung \& H. K. Choi & 좀올챙이골 & 144317 \\
\hline 620 & Schoenoplectiella wallichii (Nees) Lye & 수원고랭이 & Sun143831 \\
\hline \multirow[t]{2}{*}{621} & Scirpus karuisawensis Makino & 솔방울고랭이 & $120906-144$ \\
\hline & Orchidaceae 난초과 & & \\
\hline 622 & Cephalanthera erecta (Thunb.) Blume & 은난초 & Sun121629 \\
\hline 623 & Cephalanthera longibracteata Blume & 은대난초 & Sun153036 \\
\hline 624 & Epipactis thunbergii A. Gray & 닭의난초 & Lee0710 \\
\hline 625 & Habenaria cruciformis Ohwi & 개잠자리난초 & Lee 0810 \\
\hline 626 & Liparis kumokiri F.Maek. & 옥잠난초 & Sun104401 \\
\hline 627 & Platanthera hologlottis Maxim. & 흰제비란 & Lee0713 \\
\hline 628 & Pogonia minor (Makino) Makino & 방울새란 & Lee 0610 \\
\hline
\end{tabular}

